\title{
Metastatic cancer cells compensate for low energy supplies in hostile microenvironments with bioenergetic adaptation and metabolic reprogramming
}

\author{
YUNLONG CHENG $^{1,2^{*}}$, YUSHENG LU ${ }^{1-3^{*}}$, DOUDOU ZHANG ${ }^{1,2}$, SHU LIAN $^{1,2}$, \\ HAIYAN LIANG ${ }^{1,2}$, YUYING YE ${ }^{4}$, RUIZHI XIE ${ }^{1,2}$, SHUHUI LI ${ }^{1,2}$, \\ JIAHANG CHEN $^{1,2}$, XUHUI XUE ${ }^{5}$, JINGJING XIE ${ }^{1,2,6}$ and LEE JIA ${ }^{1,2}$
}

\begin{abstract}
${ }^{1}$ Cancer Metastasis Alert and Prevention Center, and Biopharmaceutical Photocatalysis, State Key Laboratory of Photocatalysis on Energy and Environment; ${ }^{2}$ Fujian Provincial Key Laboratory of Cancer Metastasis Chemoprevention and Chemotherapy, Fuzhou University, Fuzhou, Fujian 350116; ${ }^{3}$ Institute of Oceanography, Minjiang University, Fuzhou, Fujian 350108;

${ }^{4}$ Fujian Provincial People's Hospital Affiliated to Fujian University of Traditional Chinese Medicine, Fuzhou, Fujian 350004; ${ }^{5}$ Xi'an Children Hospital, Xi'an, Shaanxi 710003; ${ }^{6}$ School of Pharmaceutical Sciences, Xiamen University, Xiamen, Fujian 361102, P.R. China
\end{abstract}

Received January 10, 2018; Accepted June 18, 2018

DOI: $10.3892 / \mathrm{ijo} .2018 .4582$

\begin{abstract}
Metastasis accounts for the majority of cancerrelated mortalities, and the complex processes of metastasis remain the least understood aspect of cancer biology. Metabolic reprogramming is associated with cancer cell survival and metastasis in a hostile environment with a limited nutrient supply, such as solid tumors. Little is known regarding the differences of bioenergetic adaptation between primary tumor cells and metastatic tumor cells in unfavorable microenvironments; to clarify these differences, the present study aimed to compare metabolic reprogramming of primary tumor cells and metastatic tumor cells. SW620 metastatic tumor cells exhibited stronger bioenergetic adaptation in unfavorable conditions compared with SW480 primary tumor-derived cells, as determined by the sustained elevation of glycolysis and regulation of the cell cycle. This remarkable glycolytic ability of SW620 cells was associated with high expression levels of hexokinase (HK)1, HK2, glucose transporter type 1 and hypoxia-inducible factor 1 $\alpha$. Compared with SW480 cells, the expression of cell cycle regulatory proteins was effectively inhibited in SW620 cells to sustain cell survival when there was a lack of energy. Furthermore, SW620 cells exhibited a stronger mesenchymal
\end{abstract}

Correspondence to: Professor Lee Jia, Cancer Metastasis Alert and Prevention Center, Fuzhou University, 6FL Sunlight Building, Science Park, Xueyuan Road, University Town, Fuzhou, Fujian 350116, P.R. China

E-mail: jiali@fzu.edu.cn

*Contributed equally

Key words: cancer biology, cancer metastasis, bioenergetic adaptation, metabolic reprogramming, glycolysis, cell cycle, hexokinase phenotype and stem cell characteristics compared with SW480 cells; CD133 and CD166 were highly expressed in SW620 cells, whereas expression was not detected in SW480 cells. These data may explain why metastatic cancer cells exhibit greater microenvironmental adaptability and survivability; specifically, this may be achieved by upregulating glycolysis, optimizing the cell cycle and reprogramming cell metabolism. The present study may provide a target metabolic pathway for cancer metastasis therapy.

\section{Introduction}

Cancer metastasis is the principal cause of cancer-related mortality (1). The processes of metastasis are highly complex and involve a series of sequential steps that cancer cells must successfully complete, including the shedding of cells from the primary tumor into the blood circulation, survival of the circulating tumor cells in the circulation, initial seeding at a new site, extravasation into the surrounding tissue, initiation and maintenance of growth, and vascularization of the metastatic tumor $(2,3)$. Although large primary tumors are able to shed millions of cancer cells into the circulatory system every day, very few cells succeed at establishing a metastatic site at a distant organ $(2,4)$. These data indicated that the overall process of metastasis is an inefficient process. To survive in the blood or lymph and arrive at the specific organs, the escaped cells must exhibit metabolic flexibility to endure the nutrient-poor and acutely unfavorable environments $(5,6)$.

Extensive reprogramming of cellular energy metabolism is a hallmark of cancer $(7,8)$. The deregulation of cellular energetics (also called metabolic reprogramming) involves tumor cells 'rewiring' their metabolic pathways to support rapid proliferation, continuous growth, metastasis, survival and therapy resistance (9-11). Oxidative phosphorylation (OXPHOS) and glycolysis are the two principal energy 
production pathways in the cell (12). Most cancer cells exhibit a high rate of glycolysis, which not only compensates for the increased demand for adenosine 5'-triphosphate (ATP), but also contributes to cell proliferation and survival by affecting signaling pathways and enhancing the production of macromolecules, including proteins, nucleic acids and lipids $(9,13,14)$. Furthermore, tumor cells undergo considerable metabolic reprogramming to survive and metastasize within the hostile environment and the limited nutrient supply of solid tumors (15). Although it has been suggested that the extensive reprogramming of the cellular energy metabolism is a hallmark of cancer $(14,16)$, the potential molecular mechanisms by which metabolic reprogramming mediates cancer cells invasion and metastasis have yet to be elucidated. Differing from primary tumor cells, metastatic tumor cells exhibit specific metabolic characteristics that interact with the tissue microenvironment and are required for forming metastases in distant organs (8). However, metabolic changes associated with metastasis between the different environments of primary tumor cells and metastatic tumor cells remain unclear.

Epithelial-mesenchymal transition (EMT) is an important cellular process, during which cells lose epithelial characteristics and acquire mesenchymal invasive properties and stem cell-like features $(17,18)$. For example, the expression of the epithelial cell marker Epithelial cadherin (CDH1) is lost, whereas expression of the mesenchymal cell markers Neural cadherin (CDH2), fibronectin (FN) and Vimentin (VIM), and the stem cell marker CD133 are induced. The EMT process is very complex and controlled by different EMT regulators such as Zinc-finger protein SNAI1, Zinc-finger E-box-binding homeobox (ZEB), hypoxia-inducible factor (HIF)- $1 \alpha$ and Twist $(19,20)$. During the progression to metastatic competence, cancer cells acquire mesenchymal gene expression patterns and properties that confer migratory and invasive abilities, alter adhesive properties, prevent apoptosis and senescence, and activate proteolysis and motility $(19,21)$.

In the present study, two cell lines, SW480 and SW620, were selected. The cells were originally derived from the same colon cancer patient; SW480 cells were obtained from a primary tumor and SW620 cells from a lymph node metastasis (22). ATP levels and the metastatic ability and of the two cell lines were investigated to determine the different bioenergetic adaptations in the same circumstances. In addition, the expression levels of the glycolysis regulatory proteins hexokinase (HK)1 and HK2, the cell cycle regulators cyclin-dependent kinase (CDK)-2 and CDK4, as well as EMT-related mRNAs and metastasis-associated proteins, cell apoptosis, mitochondrial membrane potential $(\Delta \Psi \mathrm{m})$ and the sensitivity to fetal bovine serum (FBS) of the two cell lines were determined, to reveal the adaptive mechanisms exhibited by SW620 cells that may confer a higher metastatic ability when confronted with hostile environments. The present study provided a novel framework for understanding the metastatic cancer cells adaptations to hostile microenvironments and the formation of metastases.

\section{Materials and methods}

Antibodies and reagents. Phycoerythrin (PE)-conjugated mouse anti-human CD29 (cat. no. 557332), allophyco- cyanin-conjugated CD44 (cat. no. 559942), fluorescein isothiocyanate (FITC)-conjugated CD47 (cat. no. 556045), CD54-PE (cat. no. 555511), VIM-PE (cat. no. 562337), CD49d-FITC (cat. no. 560840), CD49e-PE (cat. no. 555617), CD51/61-PE (cat. no. 550037), Alexa Fluor 647-conjugated FN (cat. no. 563098), CD133-PE (cat. no. 566593), CD166-PE (cat. no. 559263), CD324-PE (cat. no. 562870), CD325AlexaFluor488 (cat.no.562119) andCD326-PE(cat.no.347198) and rat anti-human CD49f-PE (cat. no. 555736) antibodies were purchased from BD Pharmingen (BD Biosciences, Franklin Lakes, NJ, USA). Rabbit anti-human p21 (cat. no. 2947), p27 (cat. no. 3686), CDK2 (cat. no. 2546), CDK4 (cat. no. 12790), Cyclin D1 (cat. no. 2978), phosphorylated (p)-cell-division control protein 2 (CDC2; also known as CDK1; cat. no. 4539), $\beta$-actin (cat. no. 4970), mouse anti-human CDK6 (cat. no. 3136), Cyclin D3 (cat. no. 2936) and $\beta$-actin (cat. no. 3700) antibodies were purchased from Cell Signaling Technology, Inc. (Danvers, MA, USA). Mouse anti-HK1 (cat. no. BM1910) and mouse anti-human HK2 (cat. no. BM1911) antibodies were purchased from Boster Biological Technology (Pleasanton, CA, USA). Rabbit anti-human HIF-1 $\alpha$ (cat. no. WL01607) and glucose transporter type (GLUT)-1 (cat. no. WL01163) antibodies and an Annexin V-Light 650/propidium iodide (PI) Reagent kit (cat. no. WLA002a) were from Wanleibio Co., Ltd (Shanghai, China). Horseradish peroxidase (HRP)-conjugated goat anti-mouse (cat. no. 70-GAM007) and goat anti-rabbit (cat. no. 70-GAR007) secondary antibodies were purchased from Hangzhou MultiSciences (Lianke) Biotech Co., Ltd. (Hangzhou, China). Oligomycin A (Oligo A) was purchased from Selleck Chemicals (Houston, TX, USA). An ATP assay kit was purchased from PerkinElmer, Inc. (Waltham, MA, USA). FBS, L-15 medium and TRIzol ${ }^{\circledR}$ reagent were obtained from Thermo Fisher Scientific, Inc. (Waltham, MA, USA). PI, McCoy's 5A media, 2-Deoxy-D-glucose (2-DG), dimethyl sulfoxide, Triton X-100, RNase, 4\% paraformaldehyde, 3,3'-dihexyloxacarbocyanine iodide [DiOC6(3)] and a Bicinchoninic Acid (BCA) Protein assay kit were purchased from Sigma-Aldrich (Merck KGaA, Darmstadt, Germany). Trypsin-EDTA (0.25\%), penicillin/streptomycin (100X), tetramethylethylenediamine, ammonium persulfate, tris(hydroxymethyl)aminomethane, glycine, Tween-20, sodium dodecyl sulfate (SDS), an Efficient Chemiluminescence kit, radioimmunoprecipitation assay (RIPA) lysis buffer and bovine serum albumin were obtained from Gen-view Scientific, Inc. (El Monte, FL, USA). A PrimeScript RT Reagent kit and SYBR Premix Ex Taq PCR kit were purchased from Takara Bio, Inc. (Otsu, Japan). Polyvinylidene difluoride (PVDF) membranes, $30 \%$ polyacrylamide and dithiothreitol were purchased from Bio-Rad Laboratories, Inc. (Hercules, CA, USA).

Cell culture. The human colon cancer cell lines SW480 and SW620 were purchased from the Type Culture Collection of the Chinese Academy of Sciences (Shanghai, China) and cultured in L-15 medium containing 10\% FBS and $1 \%$ penicillin/streptomycin. All cells were maintained at $37^{\circ} \mathrm{C}$ in a humidified atmosphere of $5 \% \mathrm{CO}_{2}$, and harvested with $0.25 \%$ trypsin before use.

ATP levels assay. Intracellular ATP concentrations were determined by luminescence assay. SW480 and SW620 cells 
$\left(1 \times 10^{4}\right.$ cells/well) were sorted and collected in 96-well plates using a BD FACSAria III flow cytometer (BD Biosciences). To determine the effects of Oligo A on the intracellular ATP levels over time, cells were cultured in L-15 containing $1 \mu \mathrm{M}$ Oligo A, $1 \%$ FBS and $3 \mathrm{mg} / \mathrm{ml}$ glucose at $37^{\circ} \mathrm{C}$ for $0,0.5,1$, $2,4,6,8,12,24,36,48$ and $60 \mathrm{~h}$. To evaluate the effects of Oligo A or 2-DG on the intracellular ATP levels over time, SW620 cells $\left(1 \times 10^{4}\right.$ cells/well) were sorted and collected in 96-well plates as aforementioned. Cells were cultured in L-15 containing $1 \mu \mathrm{M}$ Oligo A, $1 \%$ FBS and $3 \mathrm{mg} / \mathrm{ml}$ glucose or L-15 containing $1 \% \mathrm{FBS}$ and $3 \mathrm{mg} / \mathrm{ml} 2-\mathrm{DG}$ at $37^{\circ} \mathrm{C}$ for $0,0.5$, $1,2,4,6,8,12,24,36,48$ and $60 \mathrm{~h}$.

To detect the ATP synthesis ability of the two cell lines in different microenvironment, cells were cultured for $24 \mathrm{~h}$ at $37^{\circ} \mathrm{C}$ in different media conditions, as follows: i) NOR, in which cells were cultured in L-15 containing $1 \%$ FBS and $3 \mathrm{mg} / \mathrm{ml}$ glucose, and cells metabolized through OXPHOS and glycolysis; ii) OXPHOS, in which cells were cultured in L-15 containing 1\% FBS without glucose, and cells metabolized through OXPHOS; iii) GLY, in which cells were cultured in L-15 containing $1 \%$ FBS, $3 \mathrm{mg} / \mathrm{ml}$ glucose and $1 \mu \mathrm{M}$ Oligo A, and cells metabolized through glycolysis; and iv) $\mathrm{UN}-(\mathrm{O}+\mathrm{G})$, L-15 containing $1 \% \mathrm{FBS}$ and $1 \mu \mathrm{M}$ Oligo A, in which cells did not metabolize through either OXPHOS or glycolysis.

ATP production was determined with the ATPlite 1-step Luminescence ATP Detection Assay system (PerkinElmer, Inc.), according to the manufacturer's protocol. Briefly, following culture in different media in 96-well plate, ATP assay solution $(100 \mu \mathrm{l})$ was added to each well and shaken at $400 \mathrm{rpm}, 37^{\circ} \mathrm{C}$ for $5 \mathrm{~min}$. Subsequently, cells were incubated in the dark for $10 \mathrm{~min}$ at $37^{\circ} \mathrm{C}$ and luminescence was measured with a TECAN M200 PRO microplate luminometer at the wavelength of 540-600 nm (Tecan Group, Ltd., Männedorf, Switzerland).

Cell surface proteins and intracellular proteins analysis. Expression of the cell surface proteins CD29, CD44, CD47, CD54, CD49d, CD49e, CD49f, CD51/61, CD133, CD166, CD324, CD325 and CD326, and the intracellular proteins VIM and FN1 were detected by BD FACSAria III flow cytometry. Briefly, SW480 and SW620 cells $\left(5 \times 10^{5}\right.$ cells/well) were seeded in 6-well plate and cultured with L-15 media containing $10 \% \mathrm{FBS}$ and $1 \%$ penicillin/streptomycin at $37^{\circ} \mathrm{C}$ for $24 \mathrm{~h}$. Subsequently, cells were collected and washed with phosphate-buffered saline (PBS) three times. The cells were centrifuged and resuspended with $200 \mu 1$ staining buffer (PBS $+1 \%$ FBS). Anti-cell surface protein antibodies were added (all 1:10) and incubated at $4^{\circ} \mathrm{C}$ in the dark for $20 \mathrm{~min}$. For intracellular proteins, cells were fixed with Fixation Buffer (BD Biosciences) for $20 \mathrm{~min}$ at $4^{\circ} \mathrm{C}$. The cells were washed with PBS and permeabilized with Perm Buffer III (BD Biosciences) for $30 \mathrm{~min}$ at room temperature. Subsequently, cells were washed with Perm/Wash Buffer I (BD Biosciences) and stained with mouse anti-human VIM-PE and mouse antihuman FN-Alexa Fluor 647 antibodies. Background staining was determined by staining with the respective isotype control antibodies. Following staining, cells were washed with staining buffer and resuspended in $500 \mu \mathrm{l}$ of the staining buffer. Flow cytometric analysis was performed on the BD FACSAria III. Data were acquired with BD FACSDiva software 6.0, and the obtained data were analyzed with FlowJo software 7.6 (FlowJo LLC, Ashland, OR, USA).

Cell apoptosis analysis. Apoptosis was examined using the Annexin V-Light 650/PI Reagent kit, according to the manufacturer's protocol. SW480 and SW620 cells $\left(5 \times 10^{5}\right.$ cells/well) were seeded in 6-well plates and cultured at $37^{\circ} \mathrm{C}$ for $24 \mathrm{~h}$ in the media conditions aforementioned: i) NOR; ii) OXPHOS; iii) GLY; iv) UN-(O+G). Following incubation, cells were collected and washed twice with PBS. Subsequently, cells were stained with $5 \mu \mathrm{l}$ Annexin-V-Light 650 and $5 \mu \mathrm{l}$ PI at room temperature for $15 \mathrm{~min}$ in the dark. Cells were analyzed with a BD FACSAria III flow cytometer and the obtained data were analyzed with FlowJo software 7.6.

Mitochondrial membrane potential $(\Delta \Psi$ m) measurement. $\Delta \Psi \mathrm{m}$ was detected by flow cytometry using DiOC6(3), as described in our previous study (23). Briefly, SW480 and SW620 cells were seeded $\left(5 \times 10^{5}\right.$ cells/well) in 6 -well plates and cultivated in the media conditions aforementioned: i) $\mathrm{UN}-(\mathrm{O}+\mathrm{G})$ and ii) GLY. Cells were cultured for $0,1,4,6$, $8 \mathrm{~h}$ and $24 \mathrm{~h}$ at $37^{\circ} \mathrm{C}$. Cells were harvested and incubated with $3 \mu \mathrm{M}$ DiOC6(3) at room temperature for $20 \mathrm{~min}$ in the dark and subsequently analyzed by the BD FACSAria III. Data were acquired with BD FACSDiva software 6.0, and the obtained data were analyzed with FlowJo software 7.6.

Western blot analysis. To evaluate the expression levels of glycolysis-regulated proteins HIF-1 $\alpha$, HK1, HK2 and GLUT1 in different microenvironments, western blotting was performed as previously described (24). SW480 and SW620 cells $\left(5 \times 10^{5}\right.$ cells/well) were seeded in 6-well plates and cultivated in three different media conditions, as aforementioned, at $37^{\circ} \mathrm{C}$ for $24 \mathrm{~h}$ : i) OXPHOS; ii) NOR: and iii) GLY. To investigate the expression of associated proteins in condition of glycolysis, 'OXPHOS' group served as the control group. To investigate the expression of glycolysis regulatory proteins (HK1 and HK2) and cell cycle regulators (CDK2, CDK4, CDK6, p21 and p27) over time when OXPHOS was suppressed, SW480 and SW620 cells $\left(5 \times 10^{5}\right.$ cells/well) were seeded in 6-well plates and cultured in L-15 supplemented with $1 \mu \mathrm{M}$ Oligo A, $1 \% \mathrm{FBS}$ and $3 \mathrm{mg} / \mathrm{ml}$ glucose at $37^{\circ} \mathrm{C}$ for $0,1,4,8,24$ and $48 \mathrm{~h}$. To determine the expression of cell cycle regulators (CDK6, Cyclin D3, Cyclin D1, pCDC2 and CDK4) in different microenvironment, cells were cultured in three different media named above as OXPHOS, GLY and NOR.

Following incubations, cells $\left(1 \times 10^{6}\right.$ cells/well $)$ were rinsed with PBS and lysed with RIPA lysis buffer on the ice for $5 \mathrm{~min}$. The lysates were centrifuged at $18,000 \mathrm{x}$ g at $4^{\circ} \mathrm{C}$ for $15 \mathrm{~min}$. Protein concentrations were determined with the BCA protein assay kit. The samples were denatured with SDS running buffer [50 mM Tris-Cl (pH 6.8), $2 \%$ (w/v) SDS, $0.1 \%$ (w/v) bromophenol blue, $20 \%$ (v/v) glycerol and $200 \mathrm{mM}$ dithiothreitol] at $100^{\circ} \mathrm{C}$ for $5 \mathrm{~min}$. Proteins $(1 \mathrm{mg} / \mathrm{ml})$ were separated by $10 \%$ SDS-PAGE and transferred onto PVDF membranes. The membranes were blocked in 5\% skim milk for $1 \mathrm{~h}$ at room temperature. The membranes were incubated with the following primary antibodies overnight at $4^{\circ} \mathrm{C}$ : Anti-HK1, anti-HK2 and anti-HIF-1 $\alpha$ (all 1:200 dilution); antiGLUT1, anti-CDK2, anti-CDK4, anti-CDK6, anti-pCDC2, 
anti-Cyclin D1, anti-Cyclin D3, p21, p27 and the loading control mouse anti-human and rabbit anti-human $\beta$-actin (all 1:1,000). Following washing with TBS + Tween-20, the membranes were incubated with an HRP-conjugated goat anti-rabbit (1:10,000 dilution) or goat anti-mouse $(1: 10,000)$ secondary antibody for $1 \mathrm{~h}$ at room temperature. Visualization was performed on ChemiDoc XPS system (Bio-Rad Laboratories, Inc.) using the Efficient Chemiluminescence kit. Densitometric analysis was performed with Image Lab 5.2.1 (Bio-Rad Laboratories, Inc.); relative protein expression levels were normalized to $\beta$-actin.

Reverse transcription-quantitative polymerase chain reaction (RT-qPCR) analysis. SW480 and SW620 (5x105 cells/ well) were seeded in 6 -well plates and cultured at $37^{\circ} \mathrm{C}$ for $24 \mathrm{~h}$ in three different media conditions, as aforementioned: i) OXPHOS; ii) NOR; and iii) GLY. RNA was extracted using TRIzol reagent, according to the manufacturer's protocol, and resuspended in $20 \mu \mathrm{l}$ RNase-free water. Following determination of the RNA concentration with Quawell Q5000 Micro-volume Spectrophotometer (Quawell Technology, Inc., San Jose, CA, USA), RNA was reverse transcribed into cDNA using the PrimeScript RT Reagent kit. cDNA was used for each of three replicates of qPCR using the SYBR Premix Ex Taq PCR kit and a CFX96 Real-Time PCR Detection system (Bio-Rad Laboratories, Inc.) with the following thermocycling conditions: Initial denaturation at $95^{\circ} \mathrm{C}$ for $30 \mathrm{sec}$; followed by 40 cycles of $95^{\circ} \mathrm{C}(5 \mathrm{sec})$ and $60^{\circ} \mathrm{C}(30 \mathrm{sec})$. Target mRNA expression levels were normalized to $\beta$-actin and calculated by the $2^{-\Delta \Delta \mathrm{Cq}}$ method (25). Results are presented as the mean \pm standard deviation (SD) of three independent experiments. mRNA expression levels were analyzed for HK1, HK2, HIF-1 $\alpha$, CDH1, CDH2, ZEB1, SNAI1, SNAI2, FN1, VIM, CD133, TWIST and $\beta$-actin; all primer sequences for PCR analysis are presented in Table I.

In addition, SW480 and SW620 cells $\left(5 \times 10^{5}\right.$ cells/well $)$ were seeded in 6-well plates and cultivated in L-15 supplemented with $1 \mu \mathrm{M}$ Oligo A, $1 \%$ FBS and $3 \mathrm{mg} / \mathrm{ml}$ glucose at $37^{\circ} \mathrm{C}$ for $0,1,4,8,24$ or $48 \mathrm{~h}$, and the mRNA expression levels of the aforementioned genes were detected by RT-qPCR.

FBS-free tolerance and sensitivity analysis. The tolerance and sensitivity of SW480 and SW620 cells to FBS deprivation was determined by starvation culture. Cells $\left(5 \times 10^{5}\right.$ cells/well $)$ were seeded in 6-well plates cultivated in FBS-free L-15 medium. The FBS-free medium was replaced every 2 days. Cell morphology and viability were observed under Zeiss Observer A1 microscope (Zeiss AG, Oberkochen, Germany).

Wound-healing migration assay. A wound-healing assay was performed to assess the migratory ability of SW480 and SW620 cells. Cells $\left(2.5 \times 10^{4}\right.$ cells/well $)$ were seeded onto a 24-well plate and cultured for $24 \mathrm{~h}$. Subsequently, a scratch was made across the cell monolayer with a pipette tip. Cells were washed three times with PBS and L-15 medium containing $0.5 \%$ FBS was added to each well. Cells were cultured in incubator at $37^{\circ} \mathrm{C}$ and cell migration within the scrape line was recorded at $0,8,24$ and $48 \mathrm{~h}$ using a light microscope (Zeiss AG); migration distance was used to evaluate migratory ability.
Table I. Primer sequences used for reverse transcription-quantitative polymerase chain reaction analyses of human colorectal cancer cells.

\begin{tabular}{|c|c|}
\hline Gene & Primer sequence $\left(5^{\prime} \rightarrow 3^{\prime}\right)$ \\
\hline HK1 & $\begin{array}{l}\text { F: AATGCTGGGAAACAAAGGT } \\
\text { R: AGAGGAATCCCTTCTTGGG }\end{array}$ \\
\hline HK2 & $\begin{array}{l}\text { F: CCTCGGTTTCCCAACTCTGC } \\
\text { R: GCTCCAAGCCCTTTCTCCAT }\end{array}$ \\
\hline HIF-1 $\alpha$ & $\begin{array}{l}\text { F: CGTTCCTTCGATCAGTTGTC } \\
\text { R: TCAGTGGTGGCAGTGGTAGT }\end{array}$ \\
\hline CDH1 & $\begin{array}{l}\text { F: CCGAGGACTTTGGCGTGGGC } \\
\text { R: TCCCTGTCCAGCTCAGCCCG }\end{array}$ \\
\hline $\mathrm{CDH} 2$ & $\begin{array}{l}\text { F: GACCCAAACAGCAACGACGGGT } \\
\text { R: CTGAGGCGGGTGCTGAATTCCC }\end{array}$ \\
\hline ZEB1 & $\begin{array}{l}\text { F: ATCCTGGGGCCTGAAGCTCAGG } \\
\text { R: TGGTGTGCCCTGCCTCTGGT }\end{array}$ \\
\hline SNAI1 & $\begin{array}{l}\text { F: GCTGCTACAAGGCCATGTCCGG } \\
\text { R: CTTGGTGCTTGTGGAGCAGGGAC }\end{array}$ \\
\hline SNAI2 & $\begin{array}{l}\text { F: GATGCCGCGCTCCTTCCTGG } \\
\text { R: TGGAGCAGCGGTAGTCCACAC }\end{array}$ \\
\hline FN1 & $\begin{array}{l}\text { F: TGCAAGGCCTCAGACCGGGT } \\
\text { R: GCGCTCAGGCTTGTGGGTGT }\end{array}$ \\
\hline VIM & $\begin{array}{l}\text { F: TTCCAAGCCTGACCTCACGGCTG } \\
\text { R: TTCCGGTTGGCAGCCTCAGAGA }\end{array}$ \\
\hline CD133 & $\begin{array}{l}\text { F: CAGAGTACAACGCCAAACCA } \\
\text { R: AAATCACGATGAGGGTCAGC }\end{array}$ \\
\hline TWIST & $\begin{array}{l}\text { F: TCCGCGTCCCACTAGCAGGC } \\
\text { R: CGCCCCACGCCCTGTTTCTT }\end{array}$ \\
\hline$\beta$-actin & $\begin{array}{l}\text { F: CAGAGTACAACGCCAAACCA } \\
\text { R: AAATCACGATGAGGGTCAGC }\end{array}$ \\
\hline
\end{tabular}

CDH1, Epithelial-cadherin; CDH2, Neural-cadherin (CDH2); FN, Fibronectin; HIF-1 $\alpha$, Hypoxia-inducible factor $1 \alpha$; HK, Hexokinase; SNAI, snail family transcriptional repressor; VIM, Vimentin; ZEB, Zinc-finger E-box-binding homeobox.

In vivo metastasis analysis. BALB/c nude mice $(\mathrm{n}=12$ females; age, 6-8 weeks; weight, $20 \mathrm{~g}$ ) were purchased from the Shanghai SLAC Laboratory Animal Co., Ltd. (Shanghai, China). Mice were housed in clean, pathogen-free rooms in an environment with controlled temperature $\left(26^{\circ} \mathrm{C}\right)$, filtered atmosphere and humidity (55\%), with a 12-h light/dark cycle, and provided free access to pellet food and water in microinsulator cages. All animals used in investigations were handled in accordance with the Guide for the Care and Use of Laboratory Animals (National Research Council, 1996). The Institutional Animal Care and Use Committee of Fuzhou University (Fuzhou, China) reviewed and approved all animal use procedures based on the above regulations, including the use of appropriate species, quality and number of animals, avoidance or minimization of discomfort, distress and pain of animals with a good scientific basis, and use of appropriate anesthesia 

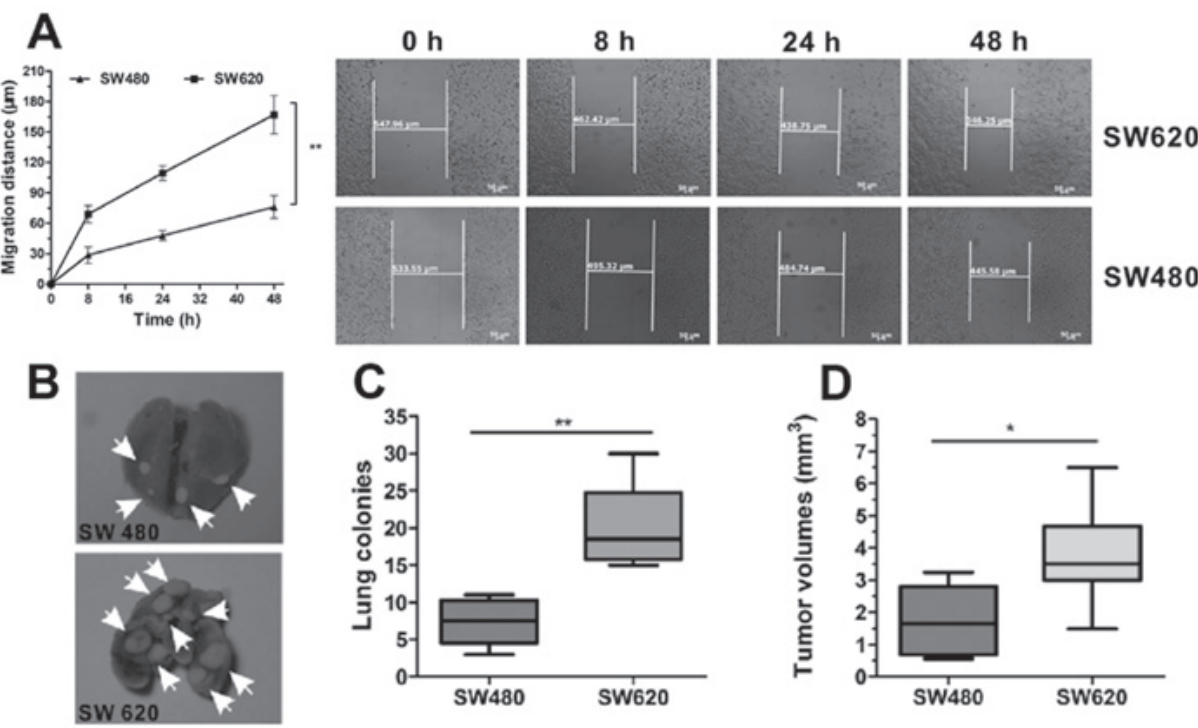

C

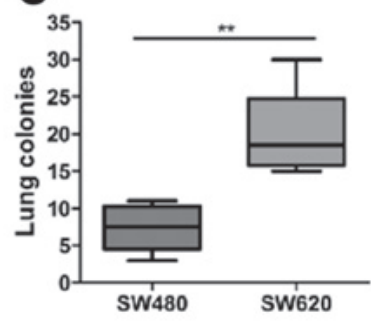

D

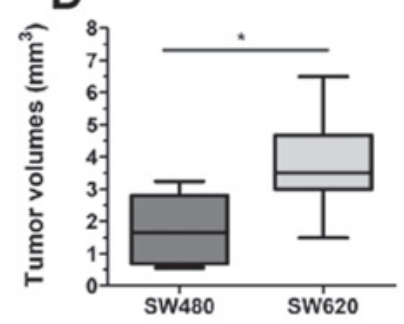

E

$\mathbf{F}$
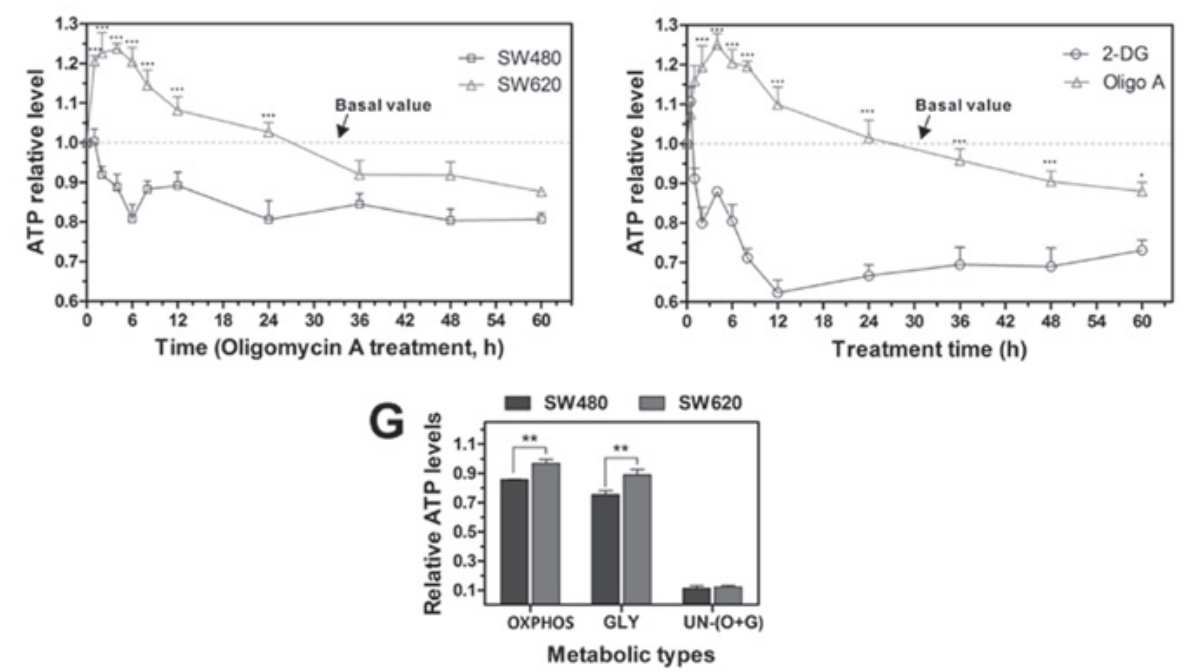

Figure 1. Comparison of metastatic potential and energy metabolism in SW480 and SW620 cells. (A) Wound-healing assay results demonstrated that SW620 cells migrated further compared with SW480 cells over the same time period. (B-D) In vivo metastasis analysis of mice injected with SW480 or SW620 cells; (B) representative photos of surface metastatic sites (white arrows) in the lungs of mice and quantitative analysis of (C) the total number of lung tumor nodules and (D) tumor nodule volumes, indicating that the SW620 cells have an increased metastatic ability and produce larger tumors compared with SW480 cells. (E) In vitro analysis of internal ATP levels in SW480 and SW620 cells treated with Oligo A $(1 \mu \mathrm{M})$ for 0-60 h. (F) Analysis of internal ATP levels in SW620 cells treated with Oligo A $(1 \mu \mathrm{M})$ or 2-DG $(1 \mathrm{mM})$ treatment. Relative ATP levels in (E) and (F) were calculated as a ratio of $0 \mathrm{~h}$. (G) Analysis of internal ATP levels in SW480 and SW620 cells cultured in various conditions to induce different metabolic processes; relative ATP levels were calculated as a ratio of NOR. Data are presented as the mean \pm standard deviation; $\mathrm{n}=3$; ${ }^{*} \mathrm{P}<0.05,{ }^{* * *} \mathrm{P}<0.01$ and ${ }^{* * *} \mathrm{P}<0.001$ vs. SW480. ATP, adenosine 5'-triphosphate; Oligo A, Oligomycin A; 2-DG, 2-deoxy-D-glucose; NOR, normal; OXPHOS, oxidative phosphorylation; GLY, glycolysis; UN-(O+G), no metabolism through OXPHOS or glycolysis.

and euthanasia. BALB/c nude mice were randomly allocated to two groups ( $\mathrm{n}=6 /$ group), which received an intravenous injection of PBS (200 $\mu 1 ; \mathrm{pH} 7.4)$ containing either SW480 or SW620 cells (1.0x10 cells) into the tail vein. At 30 days postinjection, mice were sacrificed and the lungs were excised and stained with Bouin's solution at room temperature for $24 \mathrm{~h}$ for pulmonary nodule counting.

Statistical analysis. Statistical analyses were performed with the SPSS statistical software package 22 (IBM Corp., Armonk, NY, USA). Results are expressed as the mean \pm SD. Statistical significance values were evaluated through one-way analysis of variance with a Dunnett's post hoc test. $\mathrm{P}<0.05$ was considered to indicate a statistically significant difference.

\section{Results}

SW620 cells exhibit increased energy metabolism and metastatic ability compared with SW480 cells. As previously mentioned, the SW480 cell line was established from a primary tumor, and the SW620 cell line was derived from a lymph metastatic lesion from the same patient (22). Results from the wound-healing assay indicated that SW620 cells exhibited a stronger migratory ability compared with SW480 cells; SW620 cells migrated further compared with the SW480 cells over the same period time (Fig. 1A). In vivo metastatic ability assay revealed that mice injected with SW620 cells had significantly higher numbers and total volumes of tumor nodules in the lung compared with mice injected with SW480 cells (Fig. 1B-D); tumor metastatic lesions were not observed in other organs. 


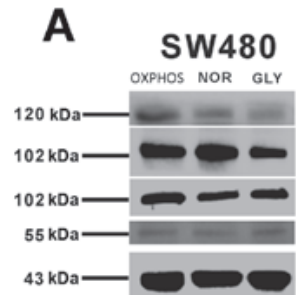

D

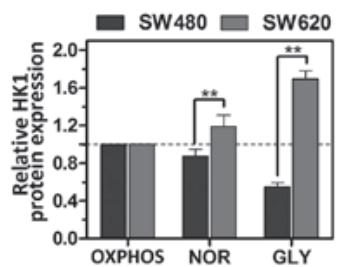

B

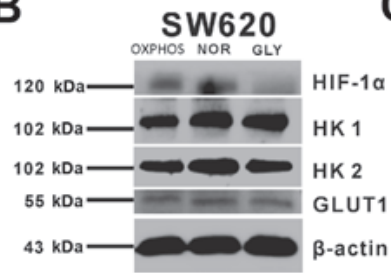

E

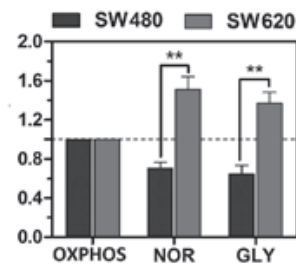

C

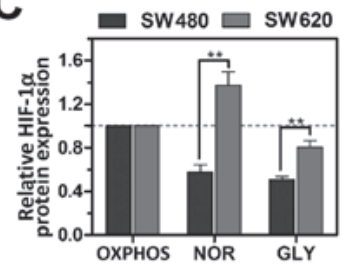

F

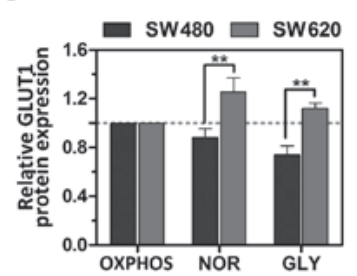

G

SW480

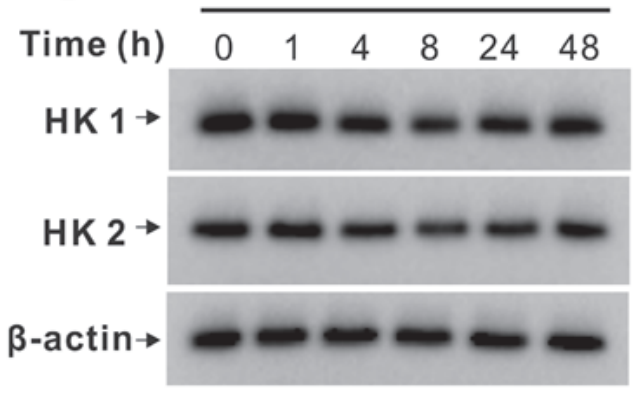

SW620
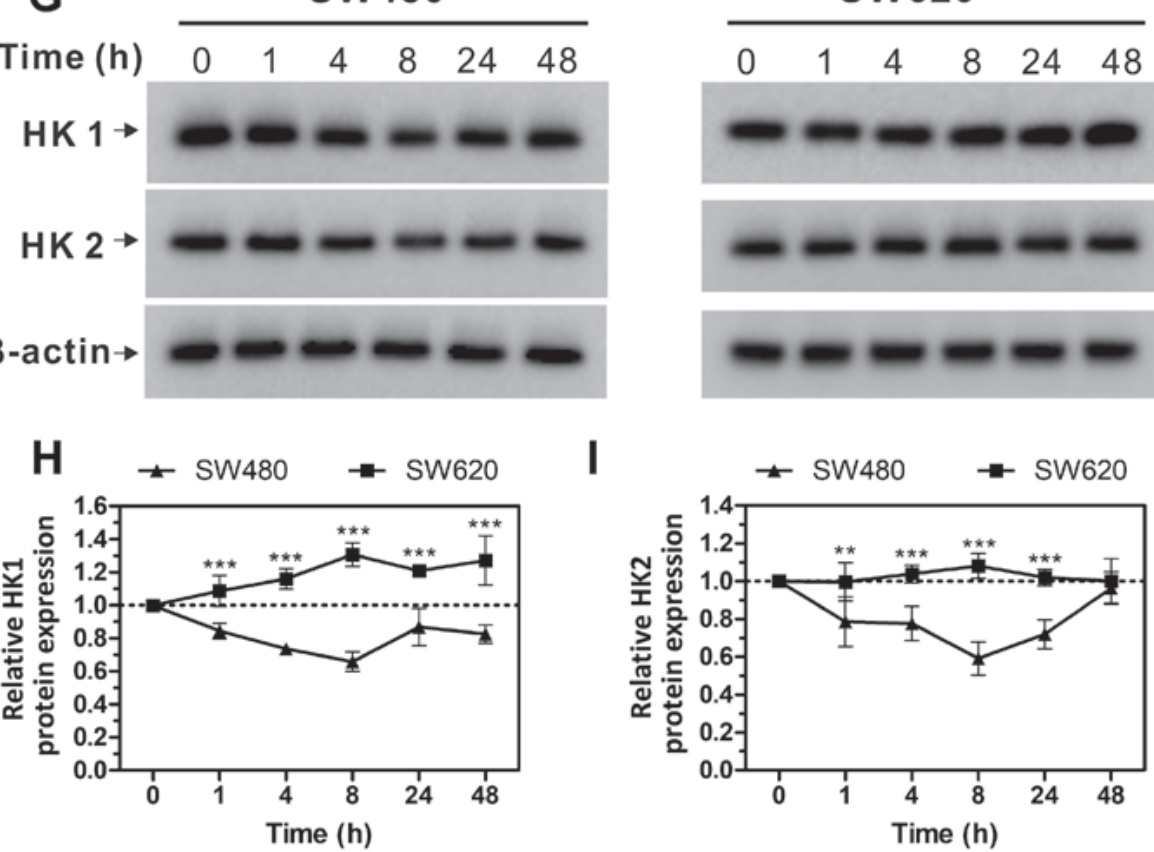

I

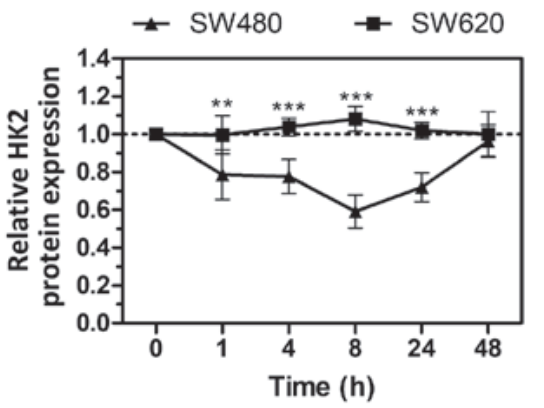

Figure 2. Expression levels of glycolysis regulation proteins in SW480 and SW620 cells with different metabolic types. (A and B) Representative western blotting images of HIF-1 $\alpha$, HK1, HK2 and GLUT1 protein expressions in (A) SW480 and (B) SW620 cells cultured in different media. (C-F) Protein expression levels from (A) and (B) were quantified using Image Lab analysis software; the relative expression levels of HIF-1 $\alpha$, HK1, HK2 and GLUT1 were calculated as a ratio of OXPHOS; $\beta$-actin was used as the loading control. (G) Western blot analysis of HK1 and HK2 protein expression levels in SW480 and SW620 cells treated with Oligomycin A $(1 \mu \mathrm{M})$ for 0-48 h. (G) Representative western blots indicating the expression of HK1 and HK2 in SW480 and SW620 cells at different treatment times. (H and I) Protein expression levels from $(\mathrm{G})$ were quantified using Image Lab analysis software, and relative expression levels of (H) HK1 and (I) HK2 were calculated as a ratio of $0 \mathrm{~h}$; $\beta$-actin was used as a loading control. Data are presented as the mean \pm standard deviation; $\mathrm{n}=3$; ${ }^{* *} \mathrm{P}<0.01$ and ${ }^{* * *} \mathrm{P}<0.001$ vs. SW480. GLUT1, glucose transporter type 1; HIF-1 $\alpha$, hypoxia-inducible factor; HK, hexokinase; NOR, normal; GLY, glycolysis; OXPHOS, oxidative phosphorylation.

Metastatic cells that escape from the primary tumor to distant organs, must possess certain traits that allow them to survive in a new microenvironment, including its conditions of nutrient scarcity (5). Cell viability and survival depend on the efficiency of ATP production through OXPHOS or glycolysis. To determine the differences in metabolic performance between SW480 and SW620, cells were treated with Oligo A, an inhibitor of ATP synthase and the OXPHOS pathway (26), or with 2-DG, a glucose molecule that has the 2-hydroxyl group replaced by hydrogen, and is thus unable to undergo further glycolysis (27), to investigate the effect on intracellular ATP levels. When OXPHOS was inhibited, the ATP levels of SW480 cells decreased rapidly and remained stable between
24 and $60 \mathrm{~h}$ post-treatment (Fig. 1E); ATP levels were maintained at $\sim 0.8$ of the basal value (basal value was determined from the same cells cultured in L-15 medium containing FBS and glucose, without Oligo A or 2-DG; in these conditions cell metabolism is through both OXPHOS and glycolysis). By contrast, at $4 \mathrm{~h}$ following Oligo A treatment, the ATP levels of SW620 cells increased to 1.2 of the basal value and decreased to the basal value at $24 \mathrm{~h}$ following treatment and remained stable at $\sim 0.9$ of the basal value between 36 and $60 \mathrm{~h}$ posttreatment. Therefore, it was speculated that when treated with Oligo A in the first $24 \mathrm{~h}$, SW620 cells may be able to initiate emergency cellular metabolism pathways to compensate for the depleted energy supply. 
A

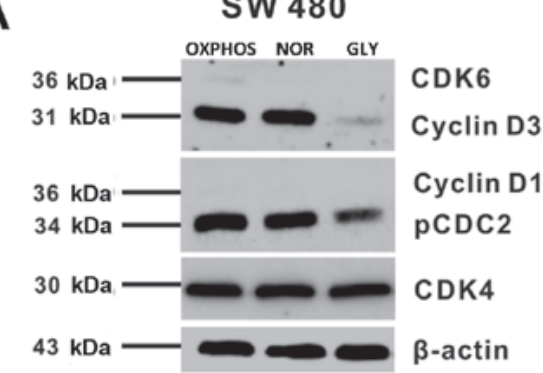

B

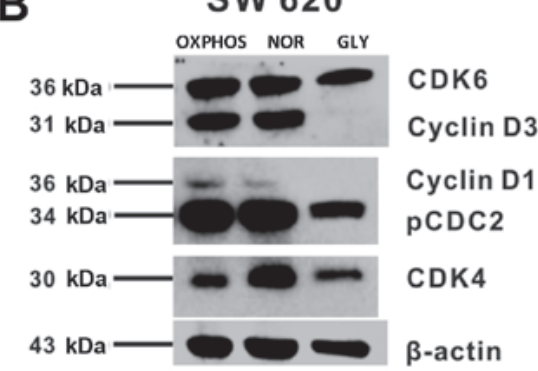

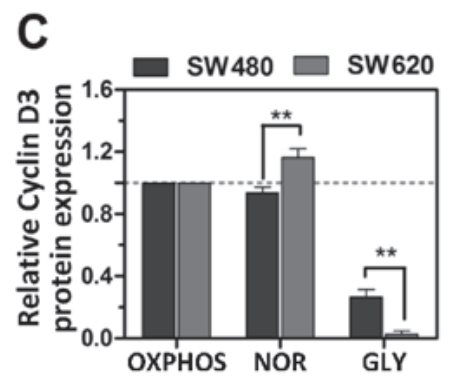
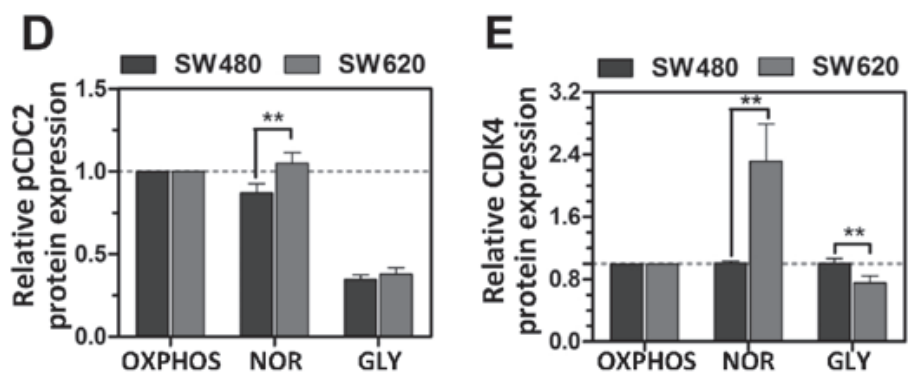

Figure 3. Expression of cell cycle regulation proteins in SW480 and SW620 cells with different metabolic types. (A and B) Representative western blotting images of CDK6, Cyclin D3, Cyclin D1, pCDC2 and CDK4 protein expression in (A) SW480 and (B) SW620 cells cultured in different media; $\beta$-actin was used as a loading control. (C-E) Protein expression levels from (A) and (B) were quantified using Image Lab analysis software, and relative expression levels of (C) Cyclin D3, (D) pCDC2 and (E) CDK4 were calculated as a ratio of the same protein in OXPHOS. Data are presented as the mean \pm standard deviation; $\mathrm{n}=3 ;{ }^{* *} \mathrm{P}<0.01$. CDC, cell division control protein; CDK, cyclin-dependent kinase; NOR, normal; GLY, glycolysis; OXPH, oxidative phosphorylation.

To evaluate whether SW620 cells upregulated OXPHOS when glycolysis was suppressed, SW620 cells were treated with 2-DG. It was determined that the ATP levels were below the basal value at all time points because of the action of 2-DG (Fig. 1F). A similar ATP suppression effect was not observed in the Oligo A group. These data suggested that glycolysis may serve a key role when cells are confronted with microenvironmental changes.

OXPHOS and glycolysis are the two principal metabolism processes to maintain cell viability and biosynthesis. In the present study, the potency of OXPHOS and glycolysis were compared in the two cell lines. Glycolysis and OXPHOS were inhibited by 2-DG or Oligo A, respectively. Cells were treated with 2-DG for $24 \mathrm{~h}$; the ATP levels in SW480 cells were 0.856 of the NOR, whereas SW620 cells exhibited a higher level, at 0.967 of the NOR (Fig. 1G). Similarly, when cells were treated with Oligo A and metabolized through glycolysis, the ATP levels were 0.755 and 0.890 of the NOR in SW480 and SW620 cells, respectively. When both OXPHOS and glycolysis were suppressed at the same time, ATP levels in the two cell lines dropped to only 0.10 of the NOR. These results indicated that SW620 cells exhibited stronger OXPHOS and glycolysis metabolism potential compared with SW480 cells.

In summary, SW620 cells exhibited higher energy metabolism capability compared with SW480 cells; when the cells were confronted with an energy supply shortage, SW620 cells exhibited a stronger capability for OXPHOS and glycolysis.

SW620 cells express high levels of glycolysis-regulated proteins. To further investigate the association between ATP levels and glycolysis, SW480 and SW620 cells were exposed to three different environments: i) OXPHOS, ii) NOR and iii) GLY. The expression levels of regulatory proteins of glycolysis, including HK1, HK2, GLUT1 and HIF-1 $\alpha$, were measured by western blot analysis. In the presence of glycolysis metabolism (NOR and GLY), the expression levels of HK1, HK2 and GLUT1 proteins in SW620 cells were all higher compared with the OXPHOS group, whereas the expression levels in SW480 cells were all decreased compared with the OXPHOS group (Fig. 2A-F). In addition, the expression levels of HIF-1 $\alpha$, HK1, HK2 and GLUT1 proteins in NOR and GLY treatments in SW620 cells were all significantly higher compared with the respective expression levels in SW480; OXPHOS was used as the control. These results suggested, compared with SW480 cells, SW620 cells are more likely to metabolize through glycolysis when glucose is sufficient.

In SW480 and SW620 cells treated with Oligo A for $48 \mathrm{~h}$, the protein expression levels of HK1 and HK2 in SW480 cells gradually decreased in the first $8 \mathrm{~h}$ of treatment and increased slightly at 24 and $48 \mathrm{~h}$; however, expression remained below the basal value ( 0 h post-treatment; Fig. 2G-I). By contrast, the expression of HK1 in SW620 cells increased gradually in the first $8 \mathrm{~h}$ of treatment and subsequently reduced slightly, remaining above the basal value (the expression levels at $0 \mathrm{~h}$ ) up to $48 \mathrm{~h}$ post-treatment (Fig. $2 \mathrm{G}$ and H). HK2 expression in SW620 did not exhibit any significant changes compared with $0 \mathrm{~h}$ (Fig. 2G-I). In conjunction with the data presented in Fig. 1E, these results indicated that when OXPHOS was suppressed, the intracellular ATP levels were positively associated with HK1 and HK2 expression.

Expression of cell cycle regulatory proteins is significantly different in different microenvironments. The study of metabolic regulations of the cell cycle is a relatively new field that is gaining increasing attention, as metabolic signals are integrated into, and coupled with, cell cycle progression $(10,28)$. In the present study, the effects of different microenvironments on the cell cycle were investigated. 
A

SW480

SW620
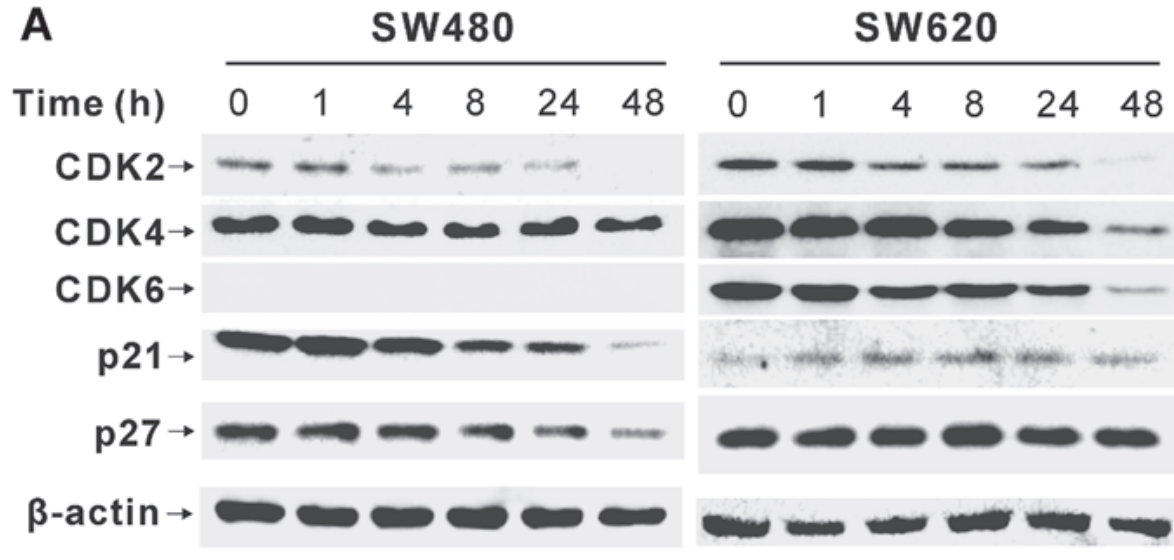

B
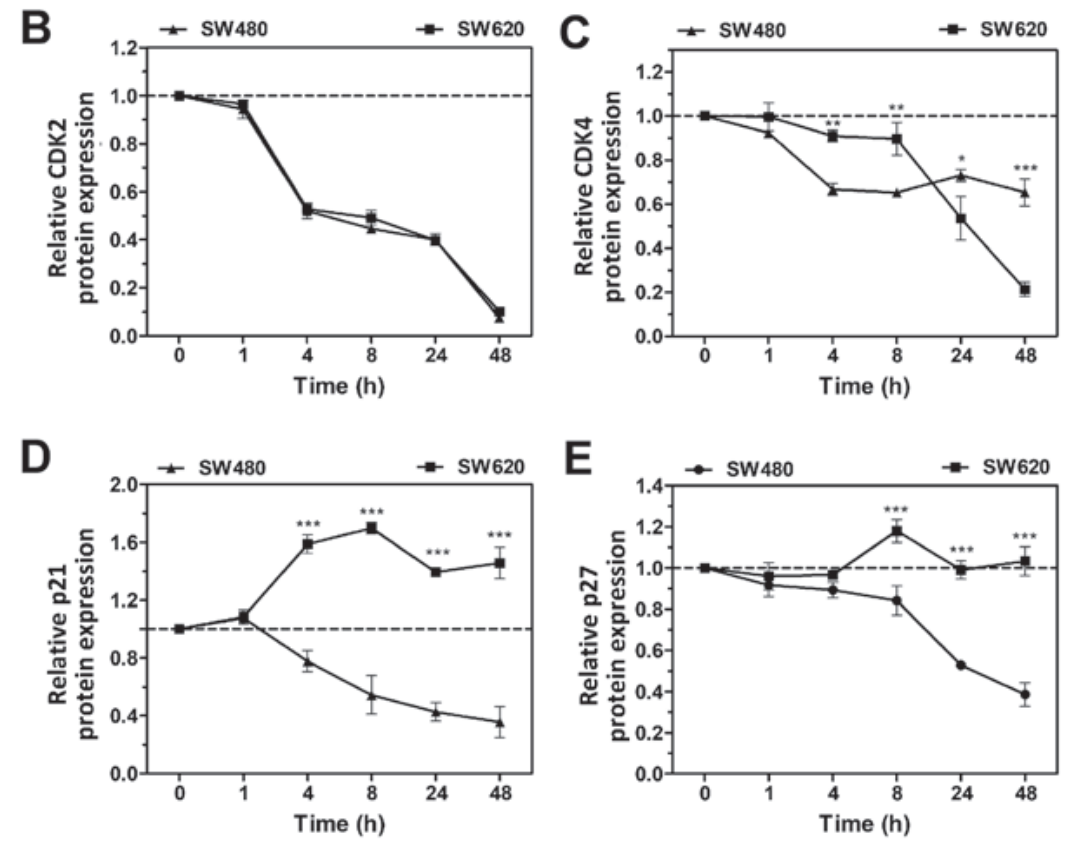

Figure 4. Expression of cell cycle checkpoint and regulation proteins in SW480 and SW620 cells treated with Oligo A over time. (A) Western blot analysis of CDK2, CDK4, CDK6, p21 and p27 protein expression levels in SW480 and SW620 treated with Oligo A (1 $\mu$ M) for 0-48 h; $\beta$-actin was used as a loading control. (B-E) Protein expression levels from (A) were quantified using Image Lab analysis software, and the relative expression levels of (B) CDK2, (C) CDK4, (D) p21 and (E) p27 were calculated. Data are presented as the mean \pm standard deviation; $n=3 ;{ }^{* *} \mathrm{P}<0.01$ and ${ }^{* * *} \mathrm{P}<0.001$ vs. SW480. CDK, cyclin-dependent kinase; Oligo A, Oligomycin A.

Tumor-associated cell cycle defects are often mediated by alterations in CDK activity (29). CDK catalytic activities are often modulated by interactions with cyclins and CDK inhibitors (28). In the present study, the expression profiles of cell cycle regulatory proteins were compared in SW480 and SW620 cells following exposure to three different microenvironments. It was identified that the expression levels of cell cycle regulatory proteins in these two cell lines were significantly different (Fig. 3). When cells metabolized by OXPHOS and glycolysis (NOR), the expression of Cyclin D3, pcdc2, and CDK4 in SW620 cells was significantly higher compared with SW480 cells, OXPHOS was used as the control (Fig. 3). However, when cells were metabolized by glycolysis (GLY), the expression of Cyclin D3 and CDK4 in SW620 cells was significantly lower compared with SW480 cells. Moreover, CDK6 and Cyclin D1 did not express in SW480 cells but its expression decreased in SW620 cells. CDC2 is a master regulator of mitosis, as it controls the centrosome cycle as well as mitotic onset, and can be activated by phosphorylation (30). Cyclin D1 and Cyclin D3 control the G1-S progression of the cell cycle in complex with CDK4 and CDK6 (28). These data indicated that SW620 cells may manage their proliferation through upregulating the expression of cyclins when energy supply is sufficient. However, in the GLY environment, the expression of Cyclin D3 and CDK4 in SW620 cells was significantly lower compared with SW480 cells (Fig. 3C and E, respectively). These results suggested that SW620 cells may inhibit the expression of positive cell cycle regulatory proteins to sustain cell survival when energy supplies are low.

Oligo A was used to inhibit OXPHOS, and the changes in cell cycle regulation were compared in SW480 and SW620 cells over a 48 -h period. The expression levels of CDK2 and CDK4 in SW480 and SW620 cells decreased over time (Fig. 4), which indicated that the cell cycle was arrested when the expression of positive cell regulatory proteins was inhibited. Similarly, the expression of CDK2 and CDK4 exhibited the same trend in SW620 cells when treated with Oligo A. CDK6 expression was not detected in SW480 cells, whereas its expression decreased in SW620 cells over time. 
A
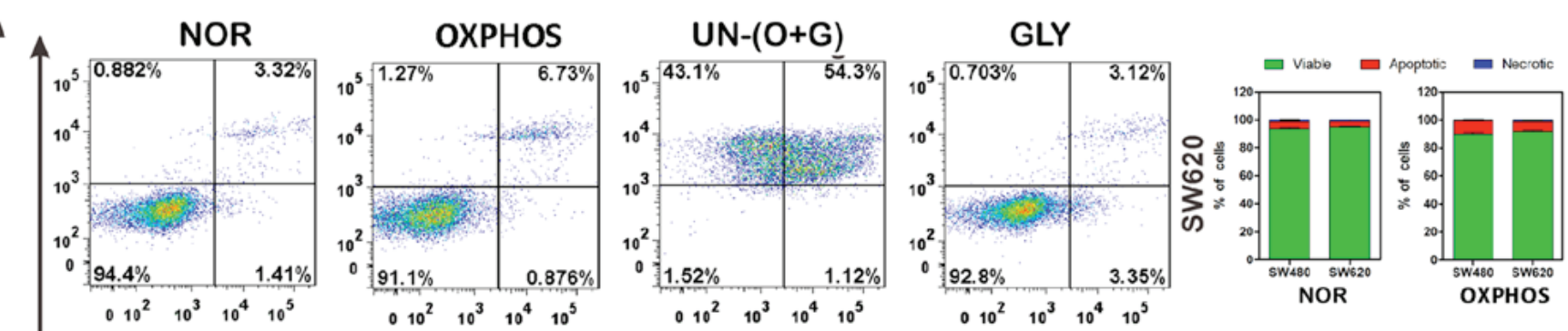

$\bar{\alpha}$
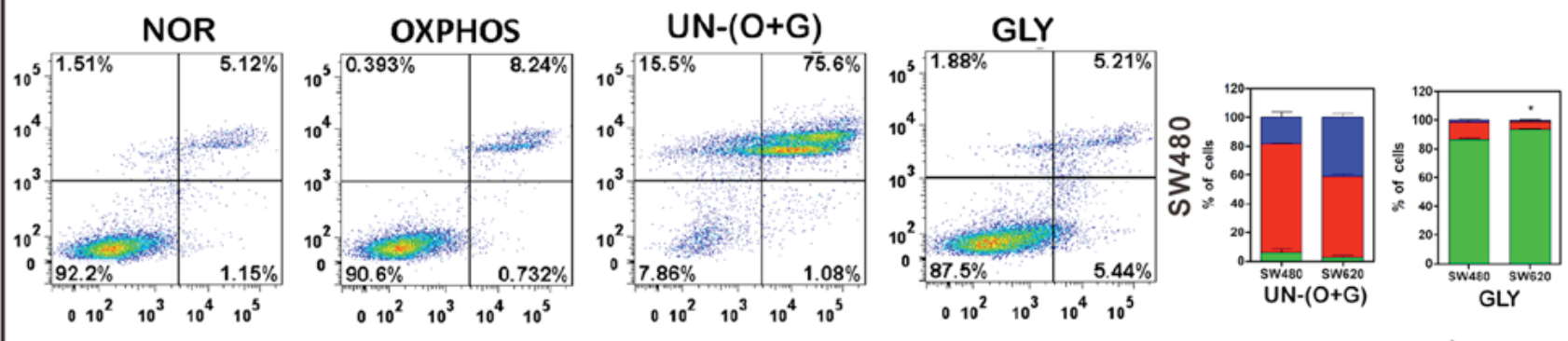

Annexin V-Light 650

B

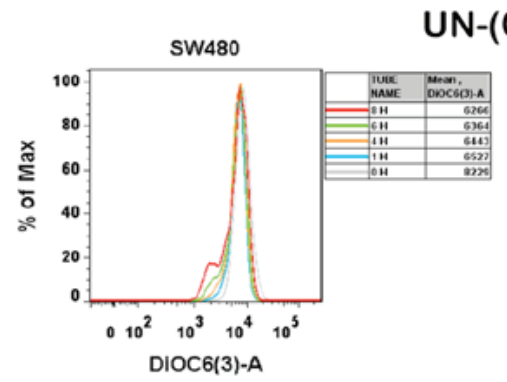

$\mathrm{UN}-(\mathrm{O}+\mathrm{G})$
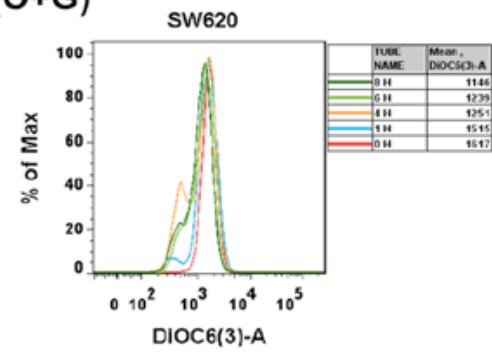

GLY
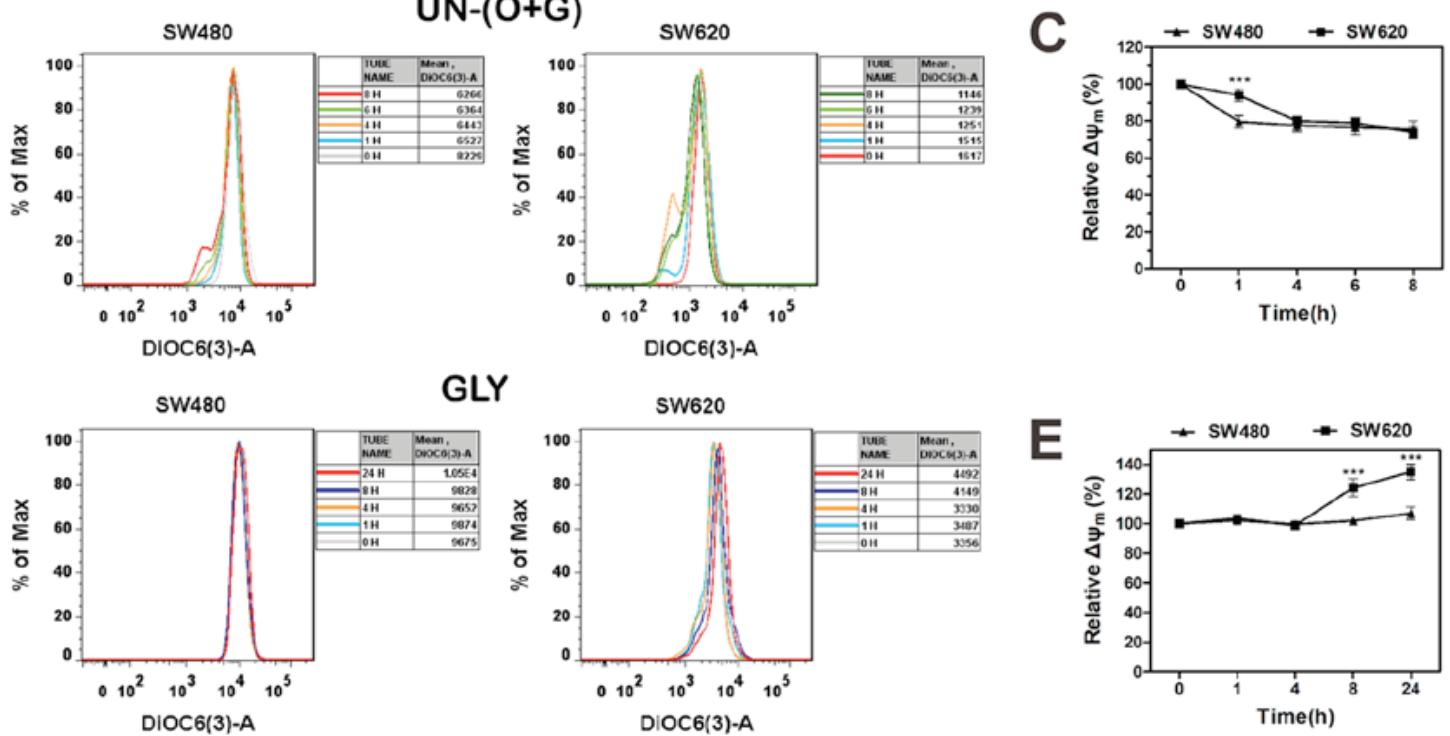

Figure 5. Apoptosis and $\Delta \Psi \mathrm{m}$ analyses of SW480 and SW620 cells in different culture environments. (A) Apoptosis was examined in SW620 and SW480 cells cultured in differing culture microenvironments. Following treatment, cells were collected, stained with PI and Annexin V and analyzed by flow cytometry. (B) $\Delta \Psi \mathrm{m}$ was examined in SW480 and SW620 cells treated with Oligo A without glucose. Following treatment, cells were collected, stained with DiOC6(3) and analyzed by flow cytometry. (C) Relative $\Delta \Psi \mathrm{m}$ of SW480 and SW620 from (B). (D) $\Delta \Psi \mathrm{m}$ was examined in SW480 and SW620 cells treated with Oligo A and glucose. (E) Relative $\Delta \Psi \mathrm{m}$ of SW480 and SW620 from (D). Data are expressed as the mean fluorescence intensities. Data are presented as the mean \pm standard deviation; $\mathrm{n}=3 ;{ }^{*} \mathrm{P}<0.05$ and ${ }^{* * *} \mathrm{P}<0.001$ vs. SW480. $\Delta \Psi \mathrm{m}$, mitochondrial membrane potential; DiOC6(3), 3,3'-dihexyloxacarbocyanine iodide; Oligo A, Oligomycin A; PI, propidium iodide; NOR, normal; OXPH, oxidative phosphorylation; GLY, glycolysis; UN-(O+G), no metabolism through OXPHOS or glycolysis.

Furthermore, protein expression levels of the CDK inhibitors p21 and p27 were upregulated in SW620 cells as the treatment time increased, whereas their expression levels in SW480 cells decreased over time (Fig. 4A, D and E). Cell cycle upstream regulatory proteins p21 and p27 may inhibit the expression of CDKs and promote cell cycle arrest $(31,32)$. These results indicated that cell cycle progression may be closely associated with intracellular metabolism.

SW620 cells exhibit stronger adaptation to different microenvironments compared with SW480 cells. The bioenergetic adaptability of SW480 and SW620 cells in different microenvironment was evaluated by apoptosis and $\Delta \Psi \mathrm{m}$ analysis. Cells in the NOR group metabolized through both OXPHOS and glycolysis; both SW480 and SW620 maintain a considerable proportion of viable cells (Fig. 5A). In the OXPH group, cells metabolized through OXPHOS and the apoptotic rates increased. In the UN-(O+G) group, cells did not metabolized through either OXPHOS or glycolysis; almost all cells are apoptotic or necrotic. In the GLY group, cells metabolized through glycolysis, and the proportion of apoptotic cells was significantly lower in SW620 cells compared with that 
A

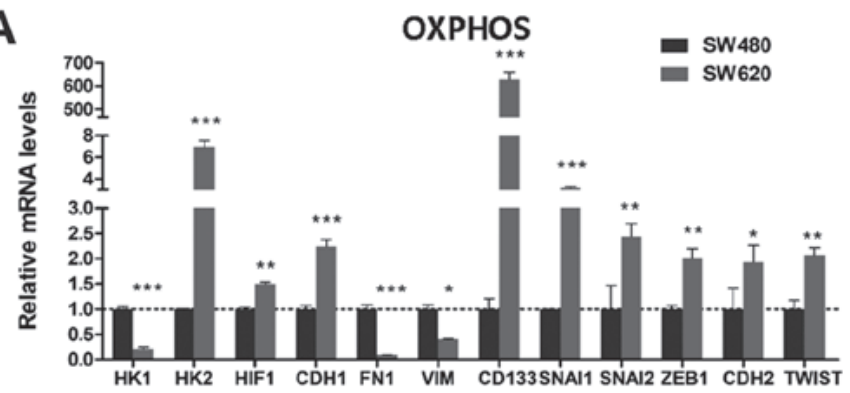

C

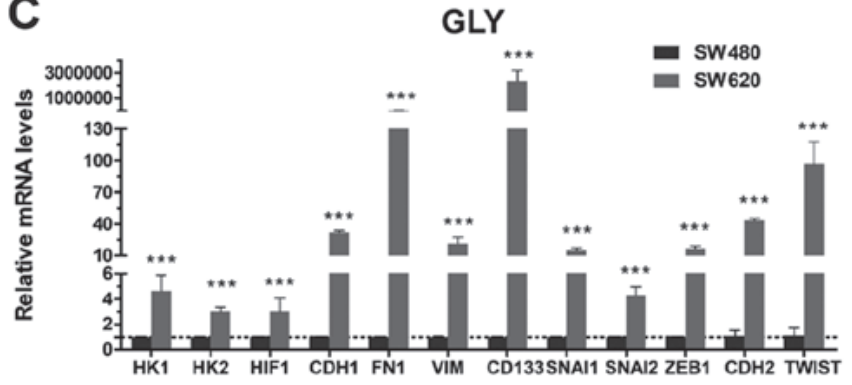

B

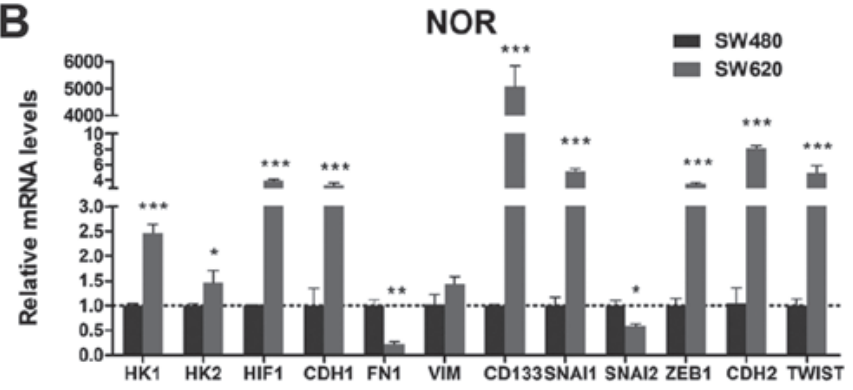

D

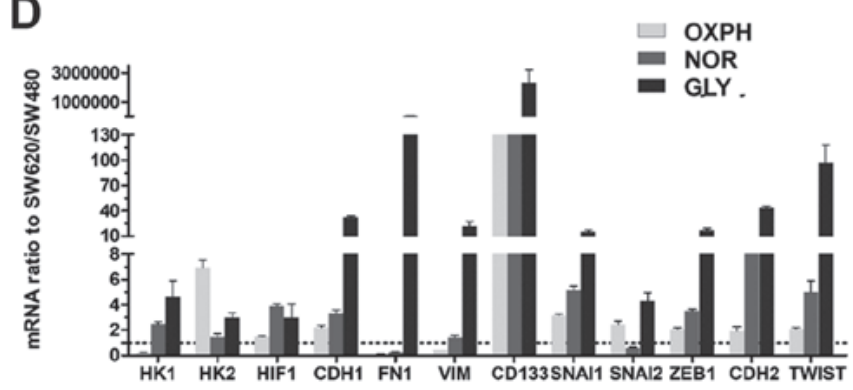

Figure 6. RT-qPCR analysis of SW480 and SW620 cells in different culture microenvironments. (A-C) RT-qPCR analysis of the relative mRNA expression levels of HK1, HK2, HIF-1 $\alpha$, CDH1, FN1, VIM, CD133, SNAI1, SNAI2, ZEB1, CDH2 and TWIST1 in SW480 and SW620 cells cultured in different media conditions; mRNA expressions were normalized to $\beta$-actin. (D) SW620/SW480 mRNA expression ratios in different types of metabolism. Data are presented as the mean \pm standard deviation; $\mathrm{n}=3 ;{ }^{*} \mathrm{P}<0.05,{ }^{* * *} \mathrm{P}<0.01$ and ${ }^{* * * *} \mathrm{P}<0.001$ vs. SW480. CDH1, Epithelial cadherin; FN1, fibronectin; HIF-1 $\alpha$, hypoxia-inducible factor; HK, hexokinase; Oligo A, Oligomycin A; OXPHOS, oxidative phosphorylation; SNAI, snail family transcriptional repressor; VIM, vimentin; ZEB, Zinc-finger E-box-binding homeobox; NOR, normal; GLY, glycolysis; OXPH, oxidative phosphorylation.

in SW480 cells. These results indicated that when the cells metabolized by glycolysis, SW620 cells exhibited a stronger anti-apoptotic ability compared with SW480 cells.

$\Delta \Psi \mathrm{m}$ is vital for sustaining the physiological function of the cellular respiration/electron transport chain to yield ATP; decreases in $\Delta \Psi \mathrm{m}$ will lead to mitochondrial dysfunction and result in apoptosis (33). Changes in $\Delta \Psi \mathrm{m}$ of SW480 and SW620 cells were evaluated when both glycolysis and OXPHOS were inhibited [UN-(O+G) group]. The $\Delta \Psi \mathrm{m}$ of SW480 cells exhibited a sudden drop at $1 \mathrm{~h}$ and gradually decreased between 1 and $8 \mathrm{~h}$, whereas the $\Delta \Psi \mathrm{m}$ of SW620 cells declined gradually during the entire experimental period when both OXPHOS and glycolysis were restrained. In addition, as UN-(O+G) SW480 and SW620 cells exhibited increased rates of apoptosis and necrosis at 24-h culturing, $\Delta \Psi \mathrm{m}$ could not be detected in cells at $24 \mathrm{~h}$ post-treatment (Fig. 5B and C). When only OXPHOS was suppressed (GLY group), the $\Delta \Psi \mathrm{m}$ of SW620 cells was significantly increased at 8 and $24 \mathrm{~h}$ following Oligo A treatment compared with $0 \mathrm{~h}$ (Fig. 5D and E). The elevation of $\Delta \Psi \mathrm{m}$ indicates the alleviation of mitochondrion impairment, and cells were protected from apoptosis (34). These data suggested that SW620 cells exhibit stronger adaptability under unfavorable conditions (Oligo A treatment) to prevent apoptosis by increasing $\Delta \Psi \mathrm{m}$.

SW620 cells exhibit stronger mesenchymal phenotypic properties compared with SW480 cells. SW620 cells are a type of metastatic cell derived from a lymph node lesion, which may possess stronger mesenchymal phenotypic properties compared with primary tumor-derived SW480 cells. To investigate the association between metabolism and EMT, the mRNA transcription levels of glycolysis regulatory proteins (HK1, HK2 and HIF-1) and EMT regulatory factors
(CDH1, FN1, VIM, CD133, SNAI1, SNAI2, ZEB1, CDH2 and TWIST) were compared in different metabolic microenvironment. When cells were cultured in medium without glucose and metabolized through OXPHOS, the mRNA transcriptional levels of the mesenchymal phenotype-associated proteins FN1 and VIM, and the key glycolysis enzyme HK1 were lower in SW620 cells compared with expression levels in SW480 cells; the other mRNA transcriptional levels were significantly higher in SW620 cells (Fig. 6A). When cells metabolized through both OXPHOS and glycolysis (NOR), the transcriptional levels of FN1 and SNAI2 were lower compared with transcriptional levels in SW480 cells; for all other genes, the transcriptional levels were significantly higher in SW620 cells (Fig. 6B). However, when OXPHOS was inhibited by treating with glucose and Oligo A, in which cells metabolized through glycolysis, all the mRNA transcriptional levels were upregulated in SW620 cells compared with SW480 cells (Fig. 6C). These data suggested that SW620 cells may regulate the expression of HK1 according to alterations in the culture environment. The HK2 mRNA expression level was higher in SW620 cells compared with SW480 cells in each type of culture condition (Fig. 6A-C), which indicated that HK2 may be a key enzyme that is upregulated in highly metastatic tumor cells. Furthermore, compared with SW480 cells, SW620 cells exhibited higher mRNA transcriptional levels of the EMT promoting factors SNAI1, TWIST and ZEB1 (Fig. 6D), which suggested that SW620 cells exhibited stronger mesenchymal cell properties and metastatic potential.

When OXPHOS was inhibited by Oligo A for $48 \mathrm{~h}$, the mRNA transcriptional levels of the key glycolysis enzymes HIF-1 $\alpha$, HK1 and HK2 were significantly upregulated in SW620 cells compared with SW480 cells (Fig. 7). These results were consistent with the data presented in Figs. 1E-H and 2G-I, 

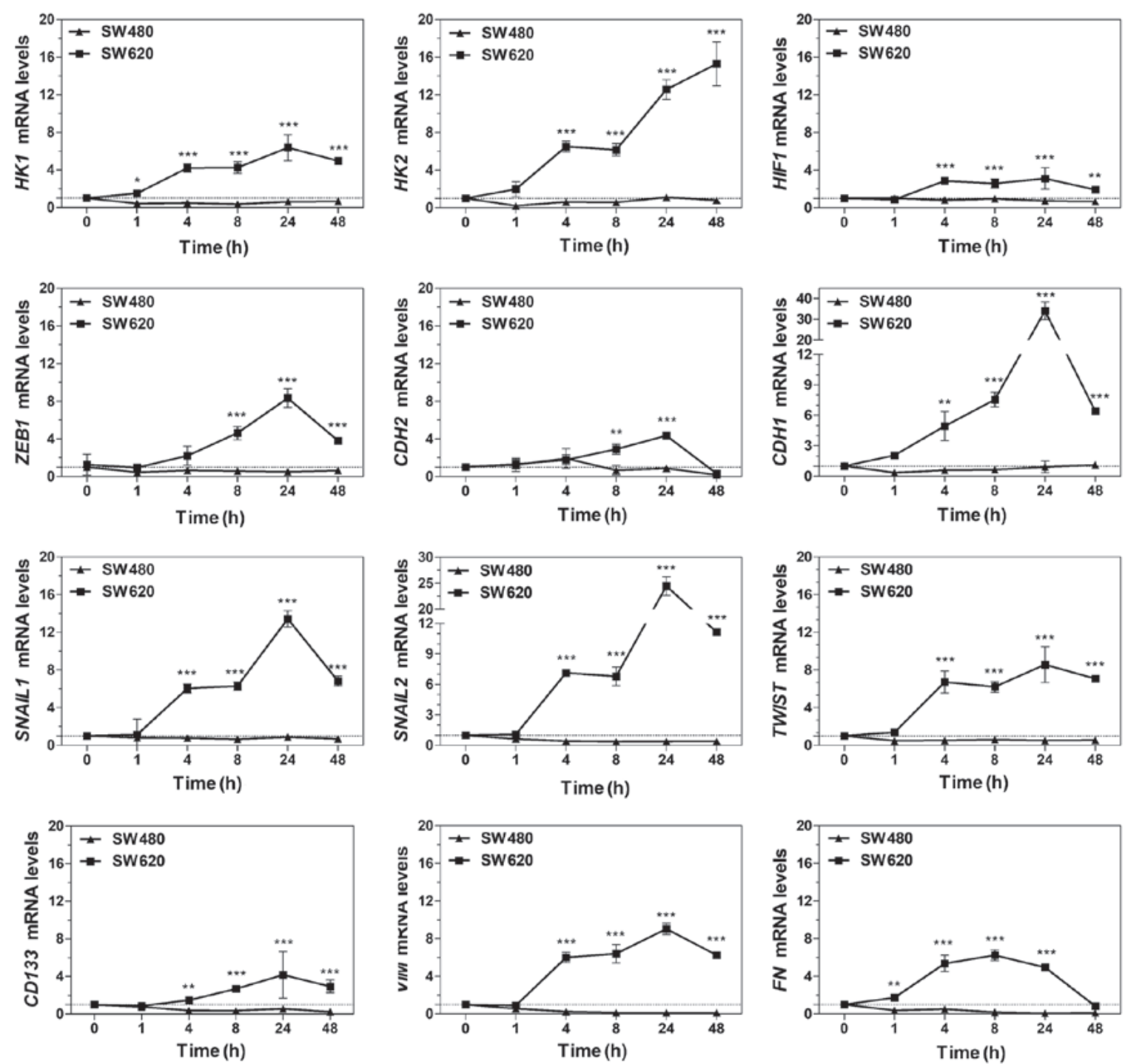

Figure 7. mRNA levels in SW480 and SW620 cells treated with Oligo A over time. Reverse transcription-quantitative polymerase chain reaction analysis of mRNA expression levels of HK1, HK2, HIF-1 $\alpha$, CDH1, CDH2, ZEB1, SNAI1, SNAI2, TWIST1, CD133, VIM and FN in SW480 and SW620 cells treated with Oligomycin A $(1 \mu \mathrm{M})$ for 0-48 h. mRNA expression levels were normalized to $\beta$-actin. Data are presented as the mean \pm standard deviation; $\mathrm{n}=3$; ${ }^{* *} \mathrm{P}<0.01$; ${ }^{* * * *} \mathrm{P}<0.001$ vs. SW480. CDH1, epithelial cadherin; CDH2, Neural-cadherin; FN1, fibronectin; HIF-1 $\alpha$, hypoxia-inducible factor; HK, hexokinase; SNAI, snail family transcriptional repressor; VIM, vimentin; ZEB, Zinc-finger E-box-binding homeobox.

which further indicated that SW620 cells may regulate the expression of HK1 and HK2 to enhance glycolysis to supplement the energy supply under conditions of energy shortage.

In addition, in SW620 cells, mRNA expression levels of the EMT promoting factors SNAI1, SNAI2, ZEB1 and TWIST, the mesenchymal phenotype-associated proteins FN1 and VIM and other EMT-related proteins CDH1, CDH2 and CD133 were upregulated over time (Fig. 7). This may result in an enhancement of migration and metastasis ability. By contrast, SW480 cells exhibited the opposite trends.

SW620 cells express CD133 and CD166. In the present study, the expression of metastasis-associated proteins CD29, CD44, CD47, CD54, VIM, CD49d, CD49e, CD49f, CD51/61, FN, CD133, CD166, CD324, CD325 and CD326 were compared in SW480 and SW620 cells by flow cytometry. The expression levels of CD44, CD54, CD133, CD166 and CD324 between SW480 and SW620 cells were markedly different; the most notable differences were that CD133 and CD166 were highly expressed in SW620 cells, but their expressions were not be detected in SW480 cells (Fig. 8). Also, the expression of CD324 in SW620 is higher than that in SW480. Conversely, the expression of CD44 and CD54 was lower in SW620 cells compared with expression in SW480 cells.

SW620 cells exhibit a stronger tolerance to FBS-free culture compared with SW480 cells. Serum is commonly used as a cell culture supplement and provides macromolecules, carrier proteins, trace elements, attachment and spreading factors, low molecular weight nutrients, hormones and growth factors; FBS is the most widely used serum and is often used to maintain cell growth and proliferation (35). In the present study, the cell growth status of SW480 and SW620 cells in FBS-free medium was compared. SW480 cells exhibited low adherence, nuclear condensation and a small degree of apoptosis (white arrows) following 5 days 


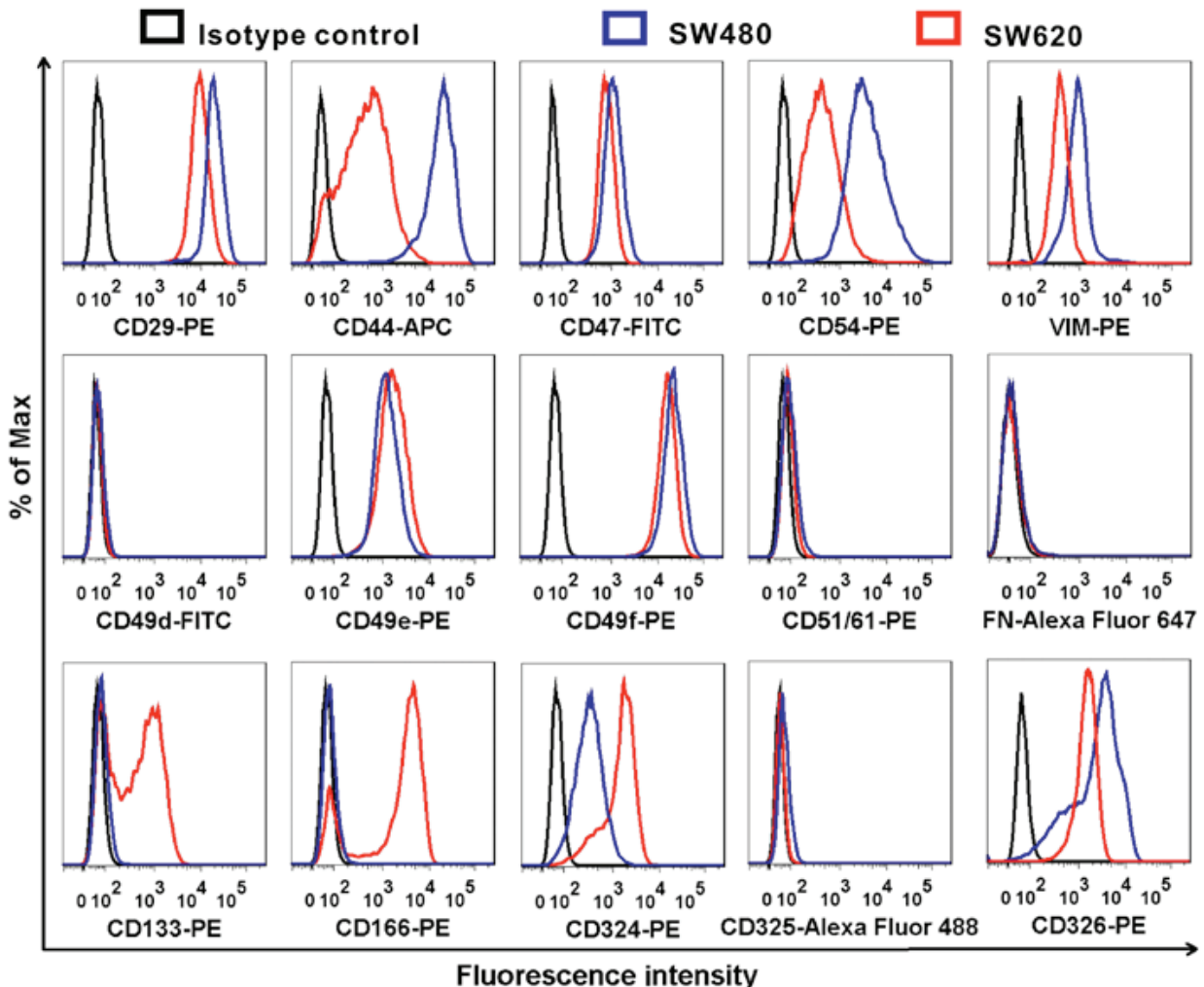

Fluorescence intensity

Figure 8. Comparison of different metastasis-associated protein expression levels between SW480 and SW620 cells. SW480 and SW620 cells were stained with CD29-PE, CD44-APC, CD47-FITC, CD54-PE, VIM-PE, CD49d-FITC, CD49e-PE, CD51/61-PE, FN-Alexa Fluor 647, CD133-PE, CD166-PE, CD324-PE, CD325-Alexa Fluor 488 and CD326-PE antibodies, and analyzed by flow cytometry. APC, allophycocyanin; FITC, fluorescein isothiocyanate; FN, fibronectin; PE, phycoerythrin; VIM, vimentin.

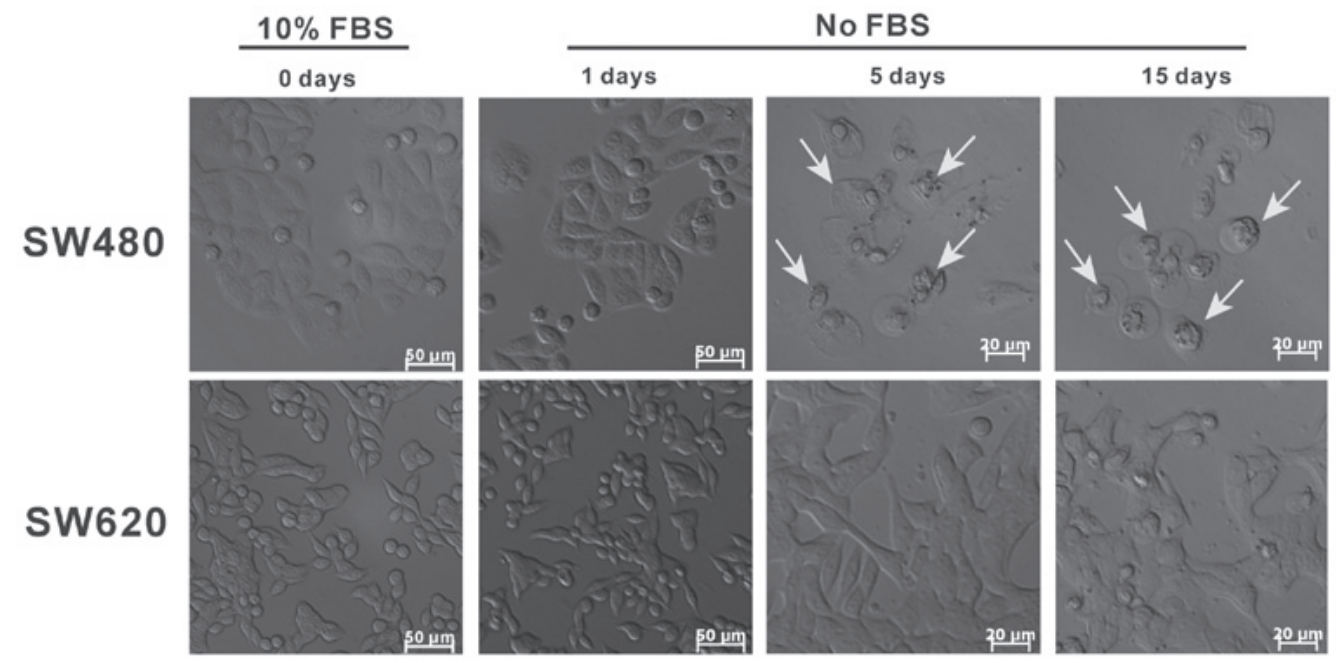

Figure 9. SW480 and SW620 cell morphology in a culture environment without FBS. Microscopy images displaying the morphology of SW480 and SW620 cells cultured in fetal bovine serum-free medium for $0,1,5$ and 15 days. White arrows: apoptotic cells.

of starvation culturing, and almost all cells had undergone apoptosis at day 15 (Fig. 9). By contrast, SW620 cells maintained high adherence, integrated morphology and a seemingly high viability following starvation culturing for 5 or 15 days. These results indicated that SW480 cells were sensitive to FBS and that SW620 cells were strongly tolerant of FBS-free medium. By comparison with SW480 cells, SW620 cells appear to be better adapted to survive in nutrient-scarce microenvironments.

\section{Discussion}

In the present study, it was observed that metastatic SW620 cells exhibited stronger bioenergetic adaptation in unfavorable situations compared with primary tumor-derived SW480 cells, through sustained elevation of glycolysis and regulation of the cell cycle. The notable glycolytic ability of SW620 cells may be associated with high expression levels of HK1, HK2, GLUT1 and HIF-1 $\alpha$. Furthermore, SW620 cells exhibited a stronger 
mesenchymal phenotype and stem cell characteristics, which may promote the metastatic process. These findings suggest that metastatic cancer cells have better adaptability and survivability in certain microenvironments owing to the upregulation of glycolysis, optimization of the cell cycle and metabolic reprogramming. In addition, a previously study established the PC3-Epi primary prostate cancer and PC3-EMT metastatic prostate cancer cell models, and reported similar findings in that glycolysis was the primary bioenergetic pathway for cell motility and cytoskeletal remodeling in mesenchymal (metastatic) cancer cells (36).

HK1 and HK2 are two isoforms of hexokinase that phosphorylate glucose to produce glucose-6-phosphate, the first step in the majority of glucose metabolism processes (37). Cellular protection and energy metabolism utilize common signaling pathways, and it has been suggested that HK2 serves a critical role not only in glycolysis, but also in cell survival $(38,39)$. In the present study, it was demonstrated that when OXPHOS was inhibited by Oligo A in the presence of glucose, SW620 cells were able to upregulate the expression of glucose metabolic enzyme HK1 and HK2, and increased the ATP levels in a short period of time. By contrast, in SW480 cells the ATP levels were decreased, and the expression of HK1 and HK2 was significantly inhibited. It has been reported that HK2 may induce cancer cell autophagy to cope with the poor microenvironment when energy supply is insufficient $(39,40)$. In addition, previous studies have also revealed that HK2 serves a significant role in AKT-mediated mitochondrial protection against opening of the mitochondrial permeability transition pores $(41,42)$, and that HK2 competes with apoptotic Bcl-2 family proteins to prevent outer mitochondrial membrane rupture $(43,44)$. These data are consistent with our present study results; when cells metabolized through OXPHOS or glycolysis, the proportion of apoptotic cells was lower among the SW620 cell population, compared with that among the SW480 cells. Flow cytometric analysis indicated that the $\Delta \Psi \mathrm{m}$ of SW620 cells was upregulated at 8 and $24 \mathrm{~h}$ inhibition of OXPHOS by Oligo A, indicating that mitochondria impairment was alleviated. This may be due to a difference in $\Delta \Psi \mathrm{m}$ between SW620 and SW480 cells. When stimulated by Oligo A, SW620 cells may have initiated a protective mechanism. The alteration of mitochondria membrane permeability may enhance cell survival, by increasing the tolerance to mitochondrial impairment. In addition, culture in FBS-free medium demonstrated that SW620 cells exhibit a stronger tolerance to nutrient-poor microenvironments, which suggested that metastatic SW620 cells possess stronger adaptability and viability in unfavorable environments. Based on these findings, it was hypothesized that SW620 cells have improved microenvironment adaptability and survivability through the upregulation of HK2 expression.

Metabolic reprogramming is considered to be a hallmark of cancer (8). Oncogene activation and loss of tumor suppressors was reported to promote metabolic reprogramming in cancers, which results in increased nutrient uptake for energetic and biosynthetic pathways (6). HIF-1 $\alpha$ serves a role in metabolic reprogramming by activating the transcription of key genes encoding metabolic enzymes $(45,46)$, including L-lactate dehydrogenase A chain (47), 3-phosphoinositidedependent protein kinase $1(48,49)$ and BCL2 $(50)$. In addition, limited nutrients within solid tumors may induce metastatic cancer cells to exhibit metabolic flexibility to sustain growth and survival (6). In the present study, HIF-1 $\alpha$ expression in SW620 cells was higher in the presence of glycolysis metabolism (normal and glycolysis environments) compared with SW480 cells, when OXPHOS was used as the control. SW620 cells exhibited stronger mesenchymal cell properties and metabolic flexibility to sustain survival through mediation of the cell cycle and EMT regulatory factors. It was observed that the ATP levels of SW480 cells cultured in Oligo A declined quickly within $24 \mathrm{~h}$, whereas the ATP levels of SW620 cells at $24 \mathrm{~h}$ were higher compared with at $0 \mathrm{~h}$. Therefore, it was speculated that, during the first $24 \mathrm{~h}$ of OXPHOS inhibition, SW620 cells may initiate glycolysis immediately to generate ATP and to enhance invasion and metastasis to enable cells to escape the hostile environment.

Complex networks regulate metastasis, including tumor-stroma interactions at the primary site, cancer cell dissemination and the microenvironment at the metastatic sites (5). To establish metastasis, cancer cells need to survive in the circulation and possess adherence and invasion properties, which are coupled to certain proteins, including CD29, CD44, CD133 and CD166 (51-53). Differences in cell surface protein expressions between SW620 and SW480 cells may serve important roles in the metastatic process. For example, CD133 is a five-transmembrane domain molecule that marks stem-like cells of various tissues and cancer types, and CD133 expression in colon cancer strongly correlates with patient survival (54). CD166 is a type of adhesion molecule and the expression of CD166 introduces a more general switch in developmental program, which connects the regulation of cell growth and cell migration (55-57). The present study results demonstrated that CD133 and CD166 were highly expressed in SW620 cells, but not be detected in SW480 cells, which indicated increased metastasis, migration and invasion, and suggested that CD133 and CD166 may be the potential targets in cancer therapy.

In conclusion, data from the present study demonstrated that metastatic cancer cells exhibited stronger metabolic flexibility and microenvironmental adaptability through metabolic reprogramming. A complex networks of cell surface proteins, the glycolysis-associated proteins HK1, HK2, GLUT1 and HIF-1 $\alpha$, cell cycle regulators and mitochondria regulate the adaptation of cancer cells in the metastatic process. However, the methods of the present study had certain limitations; the regulatory mechanisms of glycolysis-associated proteins for metastatic cancer cells bioenergetic adaptation and metabolic reprogramming will be studied through gene knockdown and overexpression, and preclinical animal experiments, in future studies. Although the detailed mechanisms underlying the observed cell behaviors require further investigation, the present study may provide the groundwork for a novel approach to cancer metastasis therapy.

\section{Acknowledgements}

The authors would like to thank The Ministry of Science and Technology of China, The National Natural Science Foundation of China, The China Postdoctoral Science Foundation and The Strait Postdoctoral Exchange Grant Program of Fujian Province. 


\section{Funding}

This research was supported by The Ministry of Science and Technology of China (grant no. 2015CB931804), The National Natural Science Foundation of China (grant nos. NSFC 81773063, U1505225, 81703555, and 81702988), The China Postdoctoral Science Foundation (grant no. 2017M620268) and The Strait Postdoctoral Exchange Grant Program of Fujian Province (grant no. 02510515).

\section{Availability of data and materials}

All data generated or analyzed during this study are included in this published article.

\section{Authors' Contributions}

YL and LJ conceived and designed the experiments. YL, YC, SL and HL performed the flow cytometry experiments. YL, DZ, SLian, YC and JX performed cells culture experiments. YL, YC, SL, SL and HL performed western blotting experiments. YL, YC, SL, RX and JC performed reverse transcriptionquantitative polymerase chain reaction experiments. YL, SL and YC performed adenosine 5'-triphosphate measurement experiments. YL, SL, YY and YC acquired and analyzed the experimental data. JX and $\mathrm{XX}$ reviewed and provide essential comments for the final version to be published. YL and YC wrote the manuscript, and LJ revised it critically for important intellectual content. All authors reviewed the manuscript.

\section{Ethical approval and consent to participate}

All animals used in this study were handled in accordance with the Guide for the Care and Use of Laboratory Animals (National Research Council, 1996). The Institutional Animal Care and Use Committee of Fuzhou University (Fuzhou, China) reviewed and approved all animal use procedures based on the above regulations.

\section{Patient consent for publication}

Not applicable.

\section{Competing interests}

The authors declare that they have no competing interests.

\section{References}

1. Sethi $\mathrm{N}$ and Kang Y: Unravelling the complexity of metastasis molecular understanding and targeted therapies. Nat Rev Cancer 11: 735-748, 2011.

2. Chambers AF, Groom AC and MacDonald IC: Dissemination and growth of cancer cells in metastatic sites. Nat Rev Cancer 2: 563-572, 2002.

3. Lu Y, Liang H, Yu T, Xie J, Chen S, Dong H, Sinko PJ, Lian S, $\mathrm{Xu} \mathrm{J}$, Wang $\mathrm{J}$, et al: Isolation and characterization of living circulating tumor cells in patients by immunomagnetic negative enrichment coupled with flow cytometry. Cancer 121: 3036-3045, 2015.

4. Labelle M and Hynes RO: The initial hours of metastasis: The importance of cooperative host-tumor cell interactions during hematogenous dissemination. Cancer Discov 2: 1091-1099, 2012.
5. Joyce JA and Pollard JW: Microenvironmental regulation of metastasis. Nat Rev Cancer 9: 239-252, 2009.

6. Boroughs LK and DeBerardinis RJ: Metabolic pathways promoting cancer cell survival and growth. Nat Cell Biol 17: 351-359, 2015.

7. Loo JM, Scherl A, Nguyen A, Man FY, Weinberg E, Zeng Z, Saltz L, Paty PB and Tavazoie SF: Extracellular metabolic energetics can promote cancer progression. Cell 160: 393-406, 2015.

8. Hanahan D and Weinberg RA: Hallmarks of cancer: The next generation. Cell 144: 646-674, 2011.

9. Vander Heiden MG, Cantley LC and Thompson CB: Understanding the Warburg effect: The metabolic requirements of cell proliferation. Science 324: 1029-1033, 2009.

10. Phan L, Chou PC, Velazquez-Torres G, Samudio I, Parreno K, Huang Y, Tseng C, Vu T, Gully C, Su CH, et al: The cell cycle regulator 14-3-3 $\sigma$ opposes and reverses cancer metabolic reprogramming. Nat Commun 6: 7530, 2015.

11. Phan LM, Yeung SC and Lee MH: Cancer metabolic reprogramming: Importance, main features, and potentials for precise targeted anti-cancer therapies. Cancer Biol Med 11: 1-19, 2014.

12. Zheng J: Energy metabolism of cancer: Glycolysis versus oxidative phosphorylation (Review). Oncol Lett 4: 1151-1157, 2012.

13. Buchakjian MR and Kornbluth S: The engine driving the ship: Metabolic steering of cell proliferation and death. Nat Rev Mol Cell Biol 11: 715-727, 2010.

14. Gatenby RA and Gillies RJ: Why do cancers have high aerobic glycolysis? Nat Rev Cancer 4: 891-899, 2004.

15. Alderton GK: Metastasis: Metabolic reprogramming in disseminated cells. Nat Rev Cancer 14: 703, 2014.

16. Postovit LM, Adams MA, Lash GE, Heaton JP and Graham CH: Oxygen-mediated regulation of tumor cell invasiveness. Involvement of a nitric oxide signaling pathway. J Biol Chem 277: 35730-35737, 2002.

17. Singh A and Settleman J: EMT, cancer stem cells and drug resistance: An emerging axis of evil in the war on cancer. Oncogene 29: 4741-4751, 2010.

18. Asnaghi L, Gezgin G, Tripathy A, Handa JT, Merbs SL, van der Velden PA, Jager MJ, Harbour JW and Eberhart CG: EMT-associated factors promote invasive properties of uveal melanoma cells. Mol Vis 21: 919-929, 2015.

19. Thiery JP, Acloque H, Huang RY and Nieto MA: Epithelialmesenchymal transitions in development and disease. Cell 139: 871-890, 2009.

20. Mani SA, Guo W, Liao MJ, Eaton EN, Ayyanan A, Zhou AY, Brooks M, Reinhard F, Zhang CC, Shipitsin M, et al: The epithelial-mesenchymal transition generates cells with properties of stem cells. Cell 133: 704-715, 2008.

21. Thiery JP and Sleeman JP: Complex networks orchestrate epithelial-mesenchymal transitions. Nat Rev Mol Cell Biol 7: 131-142, 2006.

22. Guan RJ, Ford HL, Fu Y, Li Y, Shaw LM and Pardee AB: Drg-1 as a differentiation-related, putative metastatic suppressor gene in human colon cancer. Cancer Res 60: 749-755, 2000.

23. Lu Y, Yu T, Liang H, Wang J, Xie J, Shao J, Gao Y, Yu S, Chen S, Wang L, et al: Nitric oxide inhibits hetero-adhesion of cancer cells to endothelial cells: Restraining circulating tumor cells from initiating metastatic cascade. Sci Rep 4: 4344, 2014.

24. Lian S, Lu Y, Cheng Y, Yu T, Xie X, Liang H, Ye Y and Jia L: S-nitrosocaptopril interrupts adhesion of cancer cells to vascular endothelium by suppressing cell adhesion molecules via inhibition of the NF-кB and JAK/STAT signal pathways in endothelial cells. Eur J Pharmacol 791: 62-71, 2016.

25. Livak KJ and Schmittgen TD: Analysis of relative gene expression data using real-time quantitative PCR and the 2(-Delta Delta C(T)) Method. Methods 25: 402-408, 2001.

26. Kroemer G and Pouyssegur J: Tumor cell metabolism: Cancer's Achilles' heel. Cancer Cell 13: 472-482, 2008.

27. Wick AN, Drury DR, Nakada HI and Wolfe JB: Localization of the primary metabolic block produced by 2-deoxyglucose. J Biol Chem 224: 963-969, 1957.

28. Lim S and Kaldis P: Cdks, cyclins and CKIs: Roles beyond cell cycle regulation. Development 140: 3079-3093, 2013.

29. Malumbres M and Barbacid M: Cell cycle, CDKs and cancer: A changing paradigm. Nat Rev Cancer 9: 153-166, 2009.

30. Elledge SJ: Cell cycle checkpoints: Preventing an identity crisis. Science 274: 1664-1672, 1996.

31. Shin I, Yakes FM, Rojo F, Shin NY, Bakin AV, Baselga J and Arteaga CL: PKB/Akt mediates cell-cycle progression by phosphorylation of p27(Kip1) at threonine 157 and modulation of its cellular localization. Nat Med 8: 1145-1152, 2002. 
32. Sheaff RJ, Singer JD, Swanger J, Smitherman M, Roberts JM and Clurman BE: Proteasomal turnover of p21Cip1 does not require p21Cip1 ubiquitination. Mol Cell 5: 403-410, 2000.

33. Gottlieb E, Armour SM, Harris MH and Thompson CB: Mitochondrial membrane potential regulates matrix configuration and cytochrome $c$ release during apoptosis. Cell Death Differ 10: 709-717, 2003.

34. Beltrán B, Mathur A, Duchen MR, Erusalimsky JD and Moncada S: The effect of nitric oxide on cell respiration: A key to understanding its role in cell survival or death. Proc Natl Acad Sci USA 97: 14602-14607, 2000.

35. Gstraunthaler G: Alternatives to the use of fetal bovine serum: Serum-free cell culture. ALTEX 20: 275-281, 2003.

36. Shiraishi T, Verdone JE, Huang J, Kahlert UD, Hernandez JR, Torga G, Zarif JC, Epstein T, Gatenby R, McCartney A, et al: Glycolysis is the primary bioenergetic pathway for cell motility and cytoskeletal remodeling in human prostate and breast cancer cells. Oncotarget 6: 130-143, 2015.

37. Cárdenas ML, Cornish-Bowden A and Ureta T: Evolution and regulatory role of the hexokinases. Biochim Biophys Acta 1401: 242-264, 1998

38. Pastorino JG and Hoek JB: Hexokinase II: The integration of energy metabolism and control of apoptosis. Curr Med Chem 10 $1535-1551,2003$

39. Roberts DJ, Tan-Sah VP, Ding EY, Smith JM and Miyamoto S: Hexokinase-II positively regulates glucose starvation-induced autophagy through TORC1 inhibition. Mol Cell 53: 521-533, 2014

40. Tan VP and Miyamoto S: HK2/hexokinase-II integrates glycolysis and autophagy to confer cellular protection. Autophagy 11: $963-964,2015$

41. Miyamoto S, Murphy AN and Brown JH: Akt mediates mitochondrial protection in cardiomyocytes through phosphorylation of mitochondrial hexokinase-II. Cell Death Differ 15: 521-529, 2008.

42. Sun L, Shukair S, Naik TJ, Moazed F and Ardehali H: Glucose phosphorylation and mitochondrial binding are required for the protective effects of hexokinases I and II. Mol Cell Biol 28 1007-1017, 2008

43. Robey RB and Hay N: Mitochondrial hexokinases, novel mediators of the antiapoptotic effects of growth factors and Akt. Oncogene 25: 4683-4696, 2006.

44. Pastorino JG, Shulga N and Hoek JB: Mitochondrial binding of hexokinase II inhibits Bax-induced cytochrome $c$ release and apoptosis. J Biol Chem 277: 7610-7618, 2002.

45. Semenza GL: Tumor metabolism: Cancer cells give and take lactate. J Clin Invest 118: 3835-3837, 2008.

46. Faubert B, Vincent EE, Griss T, Samborska B, Izreig S, Svensson RU, Mamer OA, Avizonis D, Shackelford DB, Shaw RJ, et al: Loss of the tumor suppressor LKB1 promotes metabolic reprogramming of cancer cells via HIF-1 $\alpha$. Proc Natl Acad Sci USA 111: 2554-2559, 2014.
47. Semenza GL, Jiang BH, Leung SW, Passantino R, Concordet JP, Maire $\mathrm{P}$ and Giallongo A: Hypoxia response elements in the aldolase A, enolase 1, and lactate dehydrogenase A gene promoters contain essential binding sites for hypoxia-inducible factor 1. J Biol Chem 271: 32529-32537, 1996.

48. Kim JW, Tchernyshyov I, Semenza GL and Dang CV: HIF-1mediated expression of pyruvate dehydrogenase kinase: A metabolic switch required for cellular adaptation to hypoxia. Cell Metab 3: 177-185, 2006.

49. Papandreou I, Cairns RA, Fontana L, Lim AL and Denko NC: HIF-1 mediates adaptation to hypoxia by actively downregulating mitochondrial oxygen consumption. Cell Metab 3: 187-197, 2006.

50. Zhang H, Bosch-Marce M, Shimoda LA, Tan YS, Baek JH, Wesley JB, Gonzalez FJ and Semenza GL: Mitochondrial autophagy is an HIF-1-dependent adaptive metabolic response to hypoxia. J Biol Chem 283: 10892-10903, 2008.

51. Dalerba P, Dylla SJ, Park IK, Liu R, Wang X, Cho RW, Hoey T, Gurney A, Huang EH, Simeone DM, et al: Phenotypic characterization of human colorectal cancer stem cells. Proc Natl Acad Sci USA 104: 10158-10163, 2007.

52. Clevers H: The cancer stem cell: Premises, promises and challenges. Nat Med 17: 313-319, 2011.

53. Du L, Wang H, He L, Zhang J, Ni B, Wang X, Jin H, Cahuzac N, Mehrpour M, Lu Y, et al: CD44 is of functional importance for colorectal cancer stem cells. Clin Cancer Res 14: 6751-6760, 2008.

54. Horst D, Kriegl L, Engel J, Kirchner T and Jung A: CD133 expression is an independent prognostic marker for low survival in colorectal cancer. Br J Cancer 99: 1285-1289, 2008.

55. Lunter PC, van Kilsdonk JW, van Beek H, Cornelissen IM, Bergers M, Willems PH, van Muijen GN and Swart GW: Activated leukocyte cell adhesion molecule (ALCAM/CD166/ MEMD), a novel actor in invasive growth, controls matrix metalloproteinase activity. Cancer Res 65: 8801-8808, 2005.

56. Levin TG, Powell AE, Davies PS, Silk AD, Dismuke AD, Anderson EC, Swain JR and Wong MH: Characterization of the intestinal cancer stem cell marker CD166 in the human and mouse gastrointestinal tract. Gastroenterology 139: 2072-2082 e2075, 2010.

57. Hansen AG, Arnold SA, Jiang M, Palmer TD, Ketova T, Merkel A, Pickup M, Samaras S, Shyr Y, Moses HL, et al: ALCAM/ CD166 is a TGF- $\beta$-responsive marker and functional regulator of prostate cancer metastasis to bone. Cancer Res 74: 1404-1415, 2014. 